\title{
A Climatology of Extreme South American Andean Cold Surges
}

\author{
Kevin C. Prince AND Clark Evans \\ Atmospheric Science Program, University of Wisconsin-Milwaukee, Milwaukee, Wisconsin
}

(Manuscript received 5 June 2018, in final form 14 August 2018)

\begin{abstract}
Cold surges represent one of several phenomena by which midlatitude features can modulate the atmosphere, both dynamically and thermodynamically, deep into the tropics. This study involves the construction of a climatology of the strongest South American cold surges that follow along the Andes Mountains to quantify the extent to which these surges modulate the atmosphere from the midlatitudes to the tropics. Cold surges occurring during June-September (austral winter) from 1980 to 2017 are considered. In this study, cold-surge events are identified using standardized anomalies of 925-hPa meridional wind and 925-hPa temperature. As compared with previous cold-surge investigations, the use of standardized anomalies better enables spatial variation in cold-surge intensity and impacts to be quantified. A strong cold surge is defined as one in which the 925 -hPa temperature is at least 3 standardized anomalies below 0 and the 925 -hPa meridional wind is at least 3 standardized anomalies above 0 on the meso- $\alpha$ scale or larger. Using these criteria, 67 events are identified. The composite cold surge is characterized by highly anomalous cold, southerly flow that originates in northern Argentina and progresses northward, significantly modulating lower-tropospheric kinematic and thermodynamic fields across the entire Amazon basin over a period of 2 to as many as 8 days.
\end{abstract}

\section{Introduction}

Cold surges are shallow features (often extending from the surface only up to $850 \mathrm{hPa}$ ) that are associated with a sharp decline in temperature, an increase in mean sea level pressure, and a shift in winds to an equatorward-directed component on the meso- $\alpha$ to synoptic scale (Colle and Mass 1995). Cold-surge events routinely occur in the lee of the Andes Mountains and Brazilian Highlands in South America (Garreaud 2000), the Rocky Mountains in North America (Colle and Mass 1995), and the Ethiopian Highlands in Africa (Wang and Fu 2004; Crossett and Metz 2017), among other locations. In South America, coldsurge occurrence is not only important economically through crop destruction (Pezza and Ambrizzi 2005), but also may represent a mechanism by which South Pacific Ocean synoptic-scale, midlatitude systems can modulate the troposphere deep into the tropics (Liebmann et al. 2009). The purpose of this study is to document the climatology of the strongest cold surges in South America, with particular focus on documenting the northward extent of these events into the tropics.

Corresponding author: Dr. Clark Evans, evans36@uwm.edu
Cold-surge events typically propagate parallel to and in the lee of major mountain ranges; consequently, coldsurge dynamics may be described in terms of rotationally trapped waves (also known as edge waves (e.g., Leathers 1986; Hsu 1987; Tilley 1990) and/or topographically trapped density currents (e.g., Mass and Albright 1987; Garreaud 2000; Pezza and Ambrizzi 2005; Metz et al. 2013). The fast propagation speed of a cold surge (up to $20 \mathrm{~m} \mathrm{~s}^{-1}$; e.g., Colle and Mass 1995), which results from the negative perturbation density associated with the cold surge, is associated with strong near-surface winds that are not in geostrophic balance (Pezza and Ambrizzi 2005). The resulting anomalously large Coriolis force directs the flow toward the adjacent mountain range. However, anomalously high static stability ensures that the potential energy required to lift the flow over the adjacent steep terrain will not be met, thus trapping the flow and directing it equatorward. More specifically, Andean cold-surge events are typically associated with an intense surface anticyclone that distorts the climatological lee trough east of the Andes and causes a sudden reversal of the lower-tropospheric winds (Pezza and Ambrizzi 2005). The associated southerly wind anomalies occur at the southern tip of South America and result from geostrophic balance between the surface anticyclone near the south Chilean 


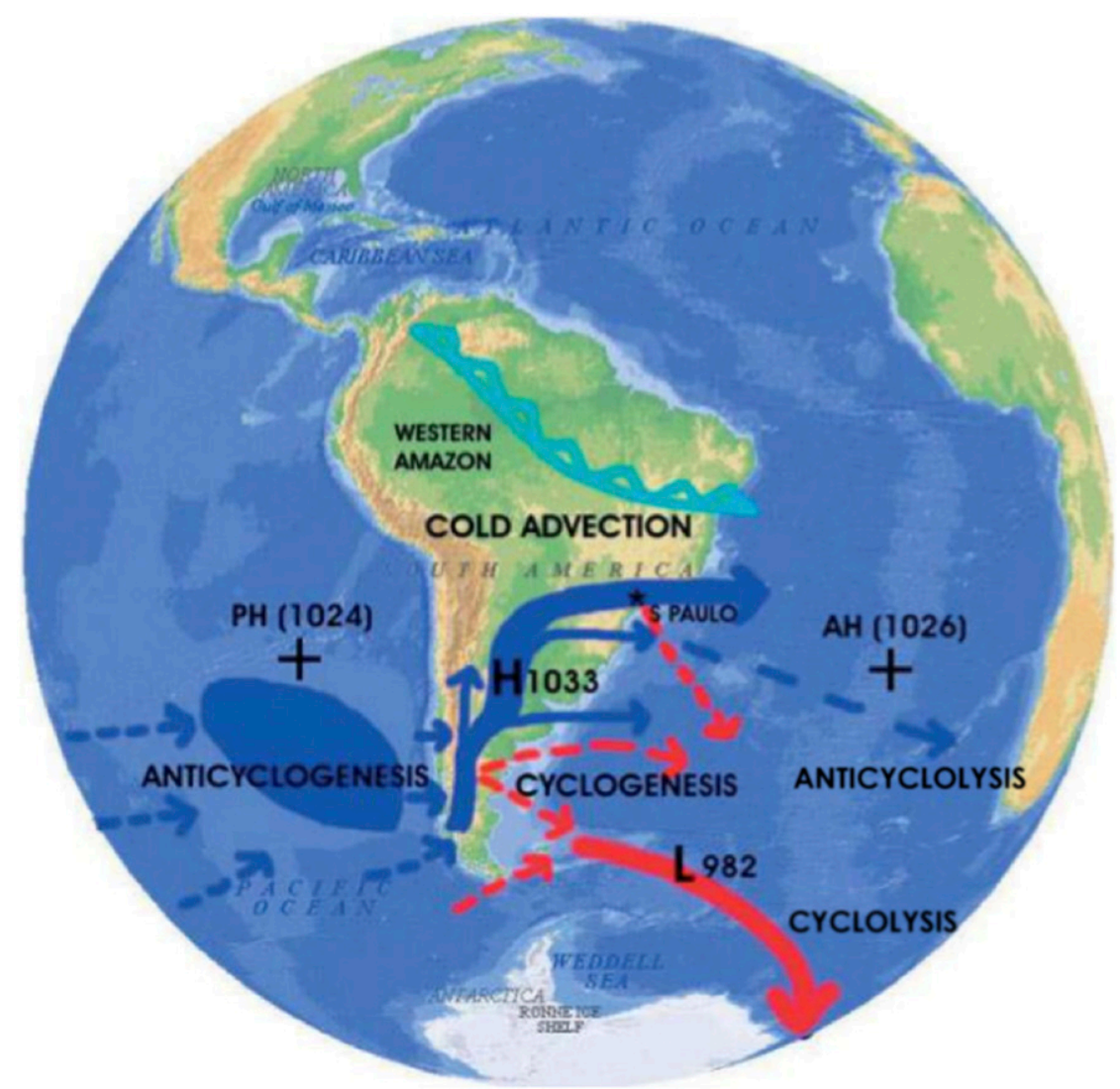

FIG. 1. Topographic map of South America with the synoptic climatology of cyclone (red) and anticyclone (blue) tracks associated with cold-air outbreaks. Thicker lines represent higher track densities, and the plus signs represent the climatological position of the Pacific and Atlantic high-pressure centers. The numbers in this picture represent the climatological-mean mean sea level pressure (hPa) associated with each feature. The cold-front line approximately shows the northern boundary of the cold-air propagation with the outbreak (from Pezza and Ambrizzi 2005).

coast and an antecedent extratropical cyclone over the Atlantic Ocean.

Cold surges in South America typically originate in northern Argentina or southern Paraguay and track parallel to the Andes Mountains and/or Brazilian Highlands as they track northward (Garreaud 2000; Lupo et al. 2001; Pezza and Ambrizzi 2005; Metz et al. 2013). In the first pathway, cold surges propagate along the Andes Cordillera through eastern Bolivia, into eastern Peru, and Colombia, before dissipating in northern Colombia and western Venezuela. Cold surges that follow along the Andes Cordillera are often associated with a major surface anticyclone centered over southern Bolivia and a highly amplified upper-tropospheric longwave pattern (Fig. 1). The second pathway constitutes cold surges that propagate through eastern Brazil along the Brazilian Highlands to the southern Atlantic Ocean, where they eventually dissipate. In contrast to cold surges that follow along the Andes Cordillera, cold surges that propagate through eastern Brazil occur in the absence of both an intense surface anticyclone and highly amplified upper-tropospheric longwave pattern (not shown). These situations occur in the presence of a surface cyclone off the eastern coast of South America, allowing maritime polar air to flow equatorward west of the cyclone's center (Lupo et al. 2001).

In South America, cold surges weaken as they travel equatorward, primarily because of surface sensible and latent heating over the Amazon basin, even during austral winter when cold surges reach peak intensity and frequency, resulting in cold surges typically losing thermodynamic potency by the time they reach northern South America (Wang and Fu 2004). Although a cold surge's temperature anomaly may weaken upon interaction with the underlying Amazon basin, its kinematic attributes are comparatively unaffected immediately thereafter (e.g., Griffin 2012) due to the gradual geostrophic adjustment to the synoptic-scale wind fields in 
response to the evolving thermodynamic fields. Cold surges along the Andes that can persist despite the intense surface heating over the Amazon end up reaching equatorial regions and have been hypothesized to potentially result in precipitation that propagates eastward with characteristics like those of a convectively coupled Kelvin wave (Liebmann et al. 2009; Metz et al. 2013).

Although Andean cold-surge structure and dynamics have previously been documented (e.g., Garreaud 2000; Pezza and Ambrizzi 2005), comparatively minimal research has focused on the extent to which the strongest of these events modulate meso- $\alpha$ - to synoptic-scale weather conditions deep into the tropics. Since variability in lower-tropospheric kinematic and thermodynamic fields is lower in equatorial regions than in the subtropics and midlatitudes (e.g., Fig. 2), and varies with time in all locations, documenting cold-surge impacts into the tropics requires an appropriate metric that intrinsically accounts for this spatiotemporally varying climatology. Standardized anomalies (Hart and Grumm 2001) provide such an internally consistent metric to quantify cold-surge strength when compared to the spatiotemporally varying climatology (Fig. 2). Standardizing the anomalies facilitates the comparison between two locations. Standardized anomalies have been used in a number of studies, with a wide range of applications. Representative examples include, but are not limited to, ensemble sensitivity analysis (e.g., Torn and Hakim 2008), the use of standardized anomalies to assess the potential for rare precipitation events (Junker et al. 2009), and the NWS Ensemble Situational Awareness Table for operational forecasting applications (e.g., http://satable.ncep.noaa.gov/).

The objective of this paper is to document the climatology of the strongest Andean cold surges, with the purpose of determining the northward extent to which these events typically propagate and influence tropical weather conditions. Particular attention is paid to the evolution of these strong surges in the lower troposphere as they propagate north and interact with the warm Amazon basin. The paper is organized as follows. The datasets and analysis procedures used are described in section 2. Section 3 documents the climatology of strong Andean cold surges and their mean structure in the days leading up to and following cold-surge initiation. A summary and discussion are provided in section 4 .

\section{Methods}

\section{a. Data}

Six-hourly data from the European Center for Medium-Range Weather Forecasts interim reanalysis

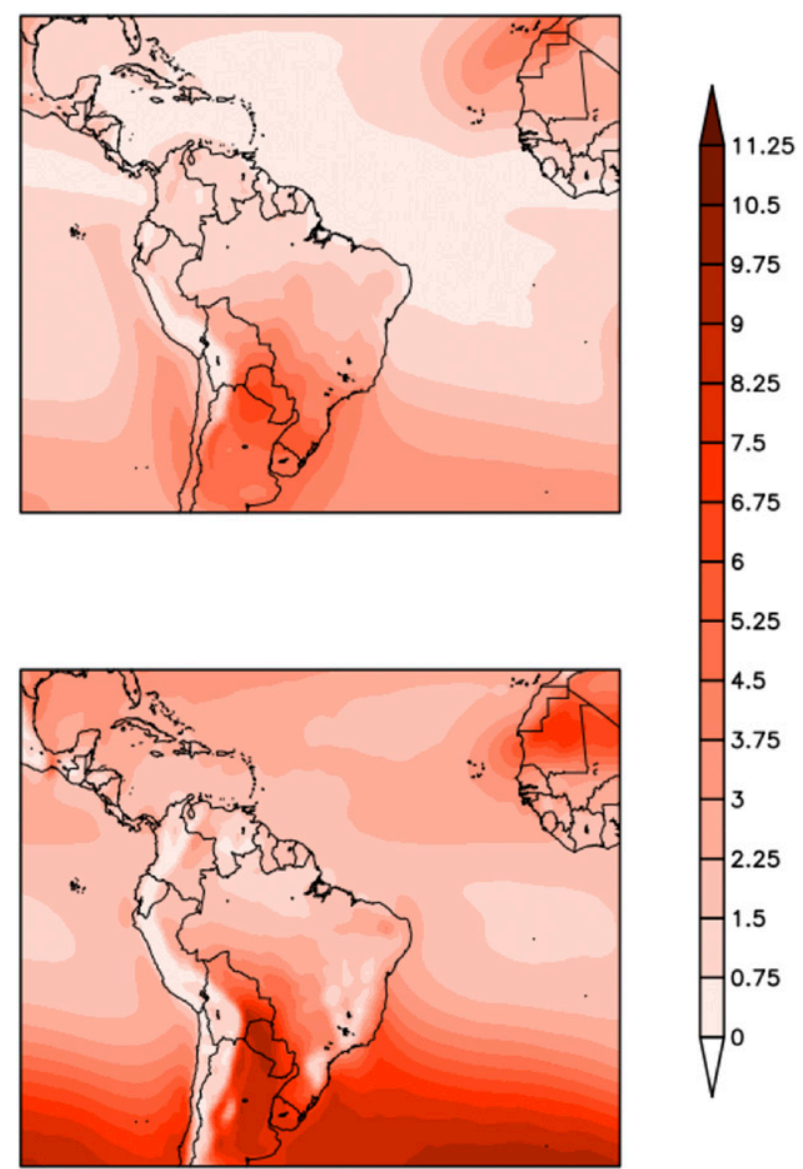

FIG. 2. May-October 1980-2010 climatological standard deviations of $925-\mathrm{hPa}$ (top) temperature $\left({ }^{\circ} \mathrm{C}\right)$ and (bottom) meridional winds $\left(\mathrm{m} \mathrm{s}^{-1}\right)$.

dataset (ERA-Interim; Dee et al. 2011) are used to identify cold surges. The dataset has roughly $80 \mathrm{~km}$ resolution on a reduced Gaussian grid with 60 isobaric levels up to $0.1 \mathrm{hPa}$. Cold surges that occur from 1 June through 30 September (122 days) from 1980 to 2017 are considered. This period encompasses austral winter, which was considered by several past studies (Garreaud 2000; Lupo et al. 2001; Pezza and Ambrizzi 2005) and is the time of year when absolute cold-surge intensity is highest. Variables considered to identify and/or document the effects of cold surges include temperature, specific humidity, zonal and meridional winds, and geopotential height, each at 1000,925 , and $850 \mathrm{hPa}$, as well as mean sea level pressure. Only one time per day (0000 UTC, near local sunset during austral winter) is considered to mitigate the effects of the diurnal cycle upon the analysis, which would be particularly noticeable in the tropics due to the strong diurnal heating over the Amazon basin. All data are analyzed and visualized utilizing the Gridded Analysis and Display 
TABLE 1. Climatological information, including start date, duration, and northern extent, for all 67 extreme cold surges along the Andean pathway from 1980 to 2017. The northern extent is determined by the northernmost latitude of the 925 -hPa temperature $N=-2.5$ standardized anomaly associated with the cold surge.

\begin{tabular}{|c|c|c|c|c|c|}
\hline Start date & Duration (days) & Northern extent & Start date & Duration (days) & Northern extent \\
\hline 2 Jul 1980 & 3 & $2.25^{\circ} \mathrm{N}$ & 11 Jul 2000 & 4 & $3^{\circ} \mathrm{N}$ \\
\hline 27 Aug 1980 & 2 & $0.75^{\circ} \mathrm{S}$ & 23 Jul 2000 & 2 & $6.75^{\circ} \mathrm{S}$ \\
\hline 16 Sep 1980 & 2 & $5.25^{\circ} \mathrm{S}$ & 25 Sep 2000 & 3 & $2.25^{\circ} \mathrm{S}$ \\
\hline 18 Jul 1981 & 4 & $9.75^{\circ} \mathrm{N}$ & 17 Jun 2001 & 8 & $9.75^{\circ} \mathrm{N}$ \\
\hline 14 Sep 1981 & 3 & $10.5^{\circ} \mathrm{N}$ & 27 Jul 2001 & 2 & $7.5^{\circ} \mathrm{S}$ \\
\hline 12 Jun 1983 & 4 & $8.25^{\circ} \mathrm{S}$ & 15 Jun 2002 & 2 & $0.75^{\circ} \mathrm{N}$ \\
\hline 8 Sep 1983 & 2 & $6^{\circ} \mathrm{S}$ & 22 Jun 2002 & 5 & $4.5^{\circ} \mathrm{N}$ \\
\hline 25 Aug 1984 & 6 & $10.5^{\circ} \mathrm{N}$ & 9 Sep 2003 & 4 & $1.5^{\circ} \mathrm{N}$ \\
\hline 28 Sep 1984 & 2 & $1.5^{\circ} \mathrm{N}$ & 20 Jun 2004 & 4 & $1.5^{\circ} \mathrm{N}$ \\
\hline 7 Jun 1985 & 7 & $9.75^{\circ} \mathrm{N}$ & 8 Aug 2004 & 3 & $4.5^{\circ} \mathrm{N}$ \\
\hline 1 Jul 1986 & 2 & $0.75^{\circ} \mathrm{N}$ & 12 Sep 2004 & 2 & $2.25^{\circ} \mathrm{N}$ \\
\hline $20 \mathrm{Jul} 1986$ & 4 & $5.25^{\circ} \mathrm{S}$ & 1 Sep 2005 & 2 & $3^{\circ} \mathrm{N}$ \\
\hline 7 Aug 1987 & 2 & $4.5^{\circ} \mathrm{S}$ & 12 Sep 2005 & 4 & $7.5^{\circ} \mathrm{N}$ \\
\hline 4 Jun 1988 & 3 & $5.25^{\circ} \mathrm{S}$ & 24 Sep 2005 & 4 & $9^{\circ} \mathrm{S}$ \\
\hline 3 Jul 1989 & 2 & $6^{\circ} \mathrm{S}$ & 26 Jul 2007 & 3 & $4.5^{\circ} \mathrm{N}$ \\
\hline 6 Jul 1989 & 5 & $12^{\circ} \mathrm{N}$ & 21 Jun 2008 & 5 & $4.5^{\circ} \mathrm{S}$ \\
\hline $21 \mathrm{Jul} 1990$ & 3 & $3^{\circ} \mathrm{S}$ & 6 Sep 2008 & 3 & $14.25^{\circ} \mathrm{S}$ \\
\hline $28 \mathrm{Jul} 1990$ & 4 & $4.5^{\circ} \mathrm{N}$ & 20 Sep 2008 & 3 & $0.75^{\circ} \mathrm{N}$ \\
\hline 10 Sep 1990 & 3 & $5.25^{\circ} \mathrm{N}$ & 3 Jun 2009 & 2 & $0.75^{\circ} \mathrm{N}$ \\
\hline 24 Sep 1990 & 2 & $0.75^{\circ} \mathrm{S}$ & 24 Jul 2009 & 2 & $5.25^{\circ} \mathrm{S}$ \\
\hline 2 Aug 1991 & 2 & $1.5^{\circ} \mathrm{S}$ & 10 Sep 2009 & 2 & $8.25^{\circ} \mathrm{S}$ \\
\hline 13 Jul 1993 & 4 & $6^{\circ} \mathrm{S}$ & 14 Jul 2010 & 6 & $2.25^{\circ} \mathrm{N}$ \\
\hline $30 \mathrm{Jul} 1993$ & 3 & $4.5^{\circ} \mathrm{S}$ & 4 Aug 2010 & 3 & $3^{\circ} \mathrm{S}$ \\
\hline 26 Jun 1994 & 2 & $3^{\circ} \mathrm{N}$ & 27 Jun 2011 & 2 & $5.25^{\circ} \mathrm{S}$ \\
\hline 9 Jul 1994 & 4 & $10.5^{\circ} \mathrm{N}$ & 2 Aug 2011 & 4 & $0.75^{\circ} \mathrm{N}$ \\
\hline 11 Aug 1994 & 2 & $2.25^{\circ} \mathrm{N}$ & 7 Jun 2012 & 3 & $3.75^{\circ} \mathrm{S}$ \\
\hline 20 Sep 1995 & 1 & $6.75^{\circ} \mathrm{S}$ & 23 Jul 2013 & 5 & $5.25^{\circ} \mathrm{N}$ \\
\hline 1 Jun 1996 & 6 & $4.5^{\circ} \mathrm{N}$ & 14 Aug 2013 & 3 & $0.75^{\circ} \mathrm{N}$ \\
\hline 27 Jun 1996 & 5 & $7.5^{\circ} \mathrm{N}$ & 25 Aug 2013 & 6 & $3.75^{\circ} \mathrm{N}$ \\
\hline 5 Aug 1997 & 5 & $4.5^{\circ} \mathrm{N}$ & 28 Jun 2014 & 3 & $2.25^{\circ} \mathrm{S}$ \\
\hline 25 Jun 1998 & 1 & $8.25^{\circ} \mathrm{S}$ & 21 Aug 2016 & 4 & $7.5^{\circ} \mathrm{S}$ \\
\hline 19 Sep 1998 & 3 & $12.75^{\circ} \mathrm{S}$ & 4 Sep 2016 & 3 & $1.5^{\circ} \mathrm{N}$ \\
\hline 4 Jul 1999 & 3 & $0.75^{\circ} \mathrm{N}$ & 18 Jul 2017 & 3 & $4.5^{\circ} \mathrm{N}$ \\
\hline 14 Aug 1999 & 4 & $5.25^{\circ} \mathrm{N}$ & Avg & 3.34 & $0.1^{\circ} \mathrm{N}$ \\
\hline
\end{tabular}

System (GrADS; Doty and Kinter 1992), and the Matrix Laboratory (MATLAB, version r2011b) software (MathWorks 2018).

\section{b. Cold-surge identification}

Fields such as mean sea level pressure (e.g., Colle and Mass 1995; Garreaud 2000), near-surface temperature (Lupo et al. 2001; Pezza and Ambrizzi 2005; Müller and Berri 2007; Metz et al. 2013), near-surface meridional wind (Vera et al. 2002), precipitation ( $\mathrm{Li}$ and $\mathrm{Fu} 2006$ ), and potential vorticity (Sprenger et al. 2013) have been previously used to identify cold surges. Further, there exist multiple permutations of how any given field from the list above has been used to identify cold surges. For example, a generalized frost (taken to represent a cold surge) was defined by Müller and Berri (2007) as a day when at least $75 \%$ of the meteorological stations within the Wet Pampa region of southern Brazil and northeast
Argentina recorded a minimum 2-m temperature less than or equal to $0^{\circ} \mathrm{C}$. Conversely, Pezza and Ambrizzi (2005) used minimum 2-m temperature in conjunction with frost observations to identify and categorize cold surges by intensity.

In this study, standardized anomalies (Hart and Grumm 2001) are used to define specific criteria that must be met in order to classify a cold-air outbreak as a strong cold surge. To calculate the standardized anomaly for any given field $X$, the climatological mean $\mu$ for the 38-yr period from 1980 to 2017 is calculated for each date between 1 June and 30 September using a 30-day centered average. The daily standard deviation $\sigma$ for the 38-yr 925-hPa meridional wind and temperature are then computed for each date. Last, the standardized anomaly $N$ is computed as the departure from the climatological mean divided by the standard deviation: 


$$
N=(X-\mu) / \sigma .
$$

All of $X, \mu$, and $\sigma$ vary in space and time, such that standardized anomalies normalize the departure of a field $X$ (here, $925-\mathrm{hPa}$ temperature and $925-\mathrm{hPa}$ meridional wind) from its climatological mean $\mu$ specific to the climatological variation $\sigma$ at that location and time.

In addition to highlighting the extent to which an event is anomalous relative to its local climatology, the standardized anomaly provides a quantitative metric by which strong cold-surge events can be identified. For a cold surge to be considered as strong, the $925-\mathrm{hPa}$ meridional wind must have a standardized anomaly of 3 or more standard deviations above normal (e.g., highly anomalous southerly flow relative to the local climatology) and the $925-\mathrm{hPa}$ temperature must have a standardized anomaly of 3 or more standard deviations below normal (e.g., highly anomalously cold temperatures relative to the local climatology). A value of 3 standardized anomalies is selected following Grumm and Hart (2001), who suggest that such an event could be deemed as highly anomalous. The standardized anomalies must cover a sufficiently large $2 \mathrm{D}$ area (meso- $\alpha$ scale; $\sim 200-2000 \mathrm{~km}$ or larger) for at least 1 day (one 0000 UTC map) to be considered as a candidate event. Each day for which these criteria are met is defined as a cold-surge day, with the end of an event defined as the first day for which these criteria are not met.

Using the criteria discussed above, 67 events are identified (Table 1), or approximately two per year. For normally distributed data, approximately $99.7 \%$ of the data for a given variable and location fall within \pm 3 standard deviations of the mean; thus, only $\sim 0.15 \%$ of the data should reside on one tail beyond \pm 3 standard deviations from the mean. Assuming normally distributed data, a strong cold surge—as defined using $925-\mathrm{hPa}$ temperature or meridional wind-during austral winter would be expected to occur at a given location once every 5-6 years. The relatively high frequency of events when compared with what is suggested by a normal distribution is due in part to the area-averaged (Fig. 3) data distribution itself (Fig. 4). To be specific, there are more events with area-averaged $925-\mathrm{hPa}$ temperature at or below 3 standard deviations below normal than would be expected for a normally distributed set of events, as is also noted in Garreaud (2000) and Metz et al. (2013). Further, the data distributions presented in Fig. 4 are for 925-hPa temperature and meridional wind standardized anomalies averaged over $5^{\circ}$ latitude $\times 5^{\circ}$ longitude regions, whereas strong cold-surge events are identified only by whether the specified standardized anomaly thresholds are on the meso- $\alpha$ scale or larger. The

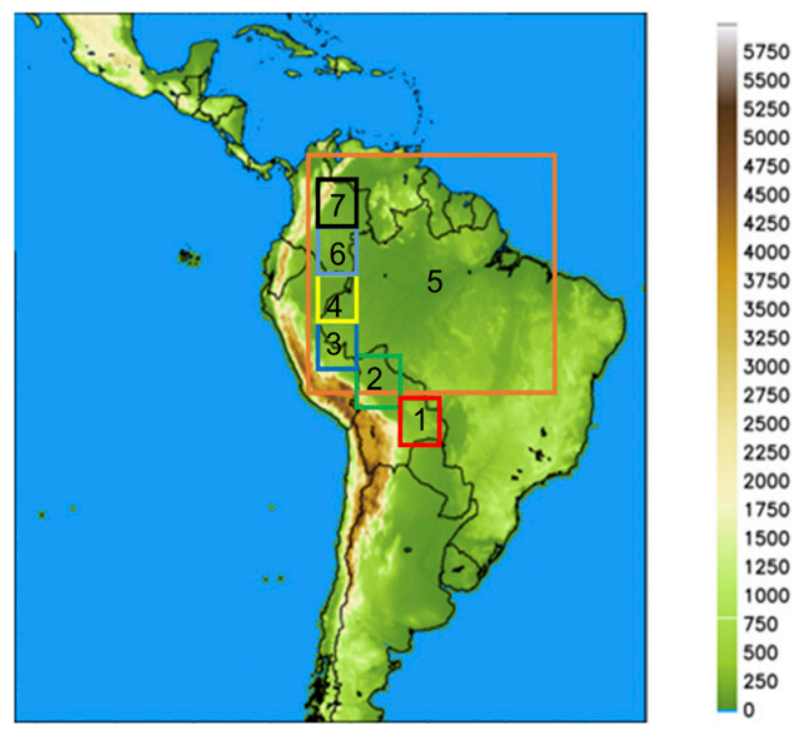

FIG. 3. Terrain height ( $\mathrm{m}$; color bar) with the area-averaged domains described in section 2 overlaid. The orange box is defined as area 5 . The remaining boxes are numbered following the typical path of an Andean cold surge: the red box is defined as area 1, the green box is defined as area 2 , the blue box is defined as area 3 , the yellow box is defined as area 4, the light blue box is defined as area 6 , and the black box is defined as area 7. Areas were numbered on the basis of the average latitude.

ERA-Interim has $0.75^{\circ} \times 0.75^{\circ}(\sim 75 \mathrm{~km})$ resolution, meaning only approximately three grid points $\left(\sim 2.25^{\circ}\right)$ in the reanalysis have to meet, or exceed, the anomaly thresholds. As a result, the analyzed data distributions are intrinsically conservative.

\section{c. Analysis methods}

To document mean cold-surge structure, longevity, intensity, and northward extent, composites are developed from the identified cases. The requirement that a cold surge be strong results in relatively small variance between events than if a broad spectrum of surge intensities is allowed, thus enabling the composites to uniquely depict cold-surge evolution for "strong" surges. Two sets of composites are generated: a startfocused composite, from 2 days before the start of the event to 5 days after the start of the event, and an endfocused composite, from 5 days before the end of each event to 2 days after the end of the event. The start- and end-focused composites help to account for variance within the composite evolutions that is due to differing cold-surge durations between the events within the composite. Given the strong similarities between the two composites (not shown), only the start-focused composite is considered herein. Cold-surge variability within the full composite is quantified using areaaveraged fields over areas that follow along the typical 
Area 1

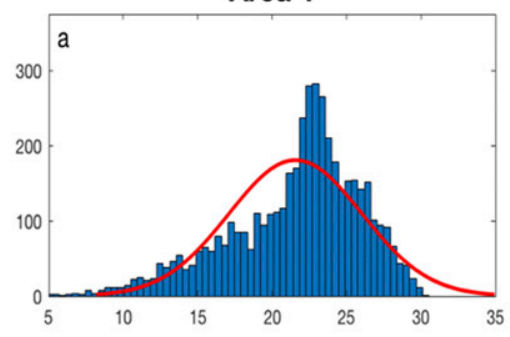

Area 3
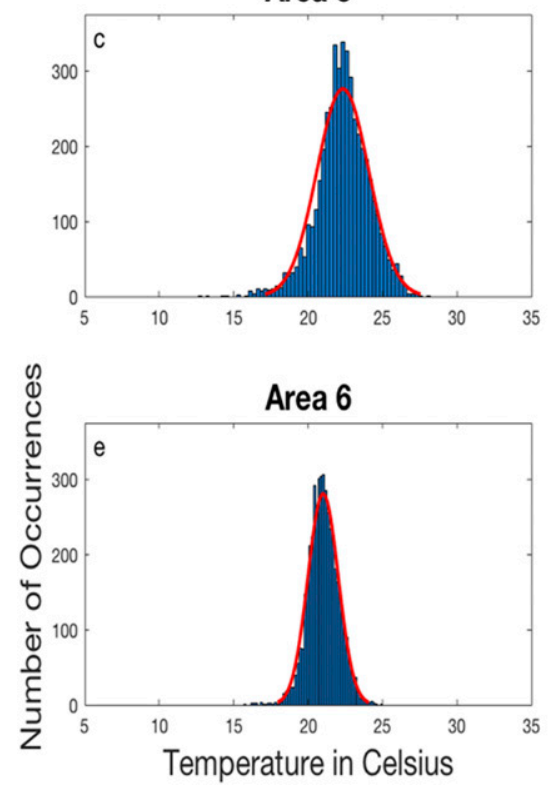

Area 2

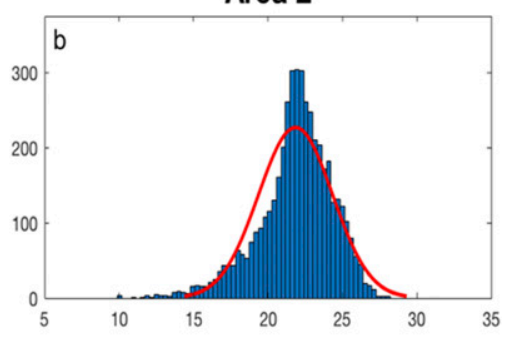

Area 4

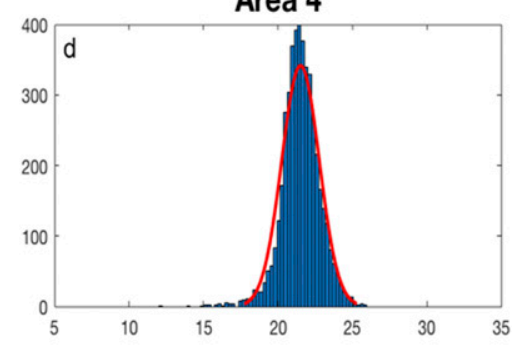

Area 7

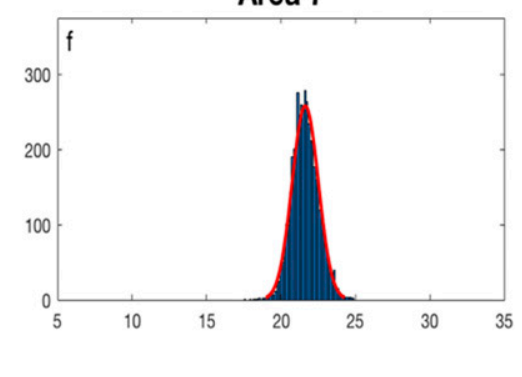

FIG. 4. Frequency of occurrence of 925 -hPa temperature $\left({ }^{\circ} \mathrm{C}\right)$ averaged over areas (a)-(d) $1-4$, respectively, and (e),(f) 6 and 7, respectively, (within $0.5^{\circ} \mathrm{C}$ bins) for all 3782 days in the dataset. The red curve in each panel depicts a normal distribution with mean and standard deviation equal to those of the underlying data.

path of an Andean cold surge into the Amazon basin (Fig. 3).

\section{Results}

\section{a. Statistics for all events}

In South America, 925-hPa temperature and meridional wind standardized anomalies of less than -2 and greater than +2 , respectively, occur every few months during austral winter (Fig. 5). Likewise, 925-hPa temperature and meridional wind standardized anomalies of less than -3 and greater than +3 , respectively, occur every $2-2.5$ years, albeit with greater uncertainty because of their limited occurrences in the dataset (Fig. 5). Note that these return periods are somewhat longer than for cold-surge events, however, given the area-averaging inherent to each region considered (a brief description of how the return rates were calculated can be found in the caption for Fig. 5).

Although the cold-surge identification criteria utilized herein identify the strongest of the cold surges during austral winter, they do not explicitly guarantee that the associated departures from normal are statistically significant to greater than or equal to $95 \%$ confidence. Given that $925-\mathrm{hPa}$ temperature is approximately normally distributed outside the cold-surge origination region of northern Argentina (Fig. 4), a Student's $t$ test is used test whether the standardized anomalies are nonzero. (Note that given the small sample size, bootstrapping is used to generate 10000 synthetic sets of 67 anomalies randomly chosen from all 4636 days in the full dataset before testing for significance.). In general, cold-surge standardized anomalies for both 925-hPa temperature and meridional wind are nonzero to $90 \%-95 \%$ confidence over a $1-2$-day period 

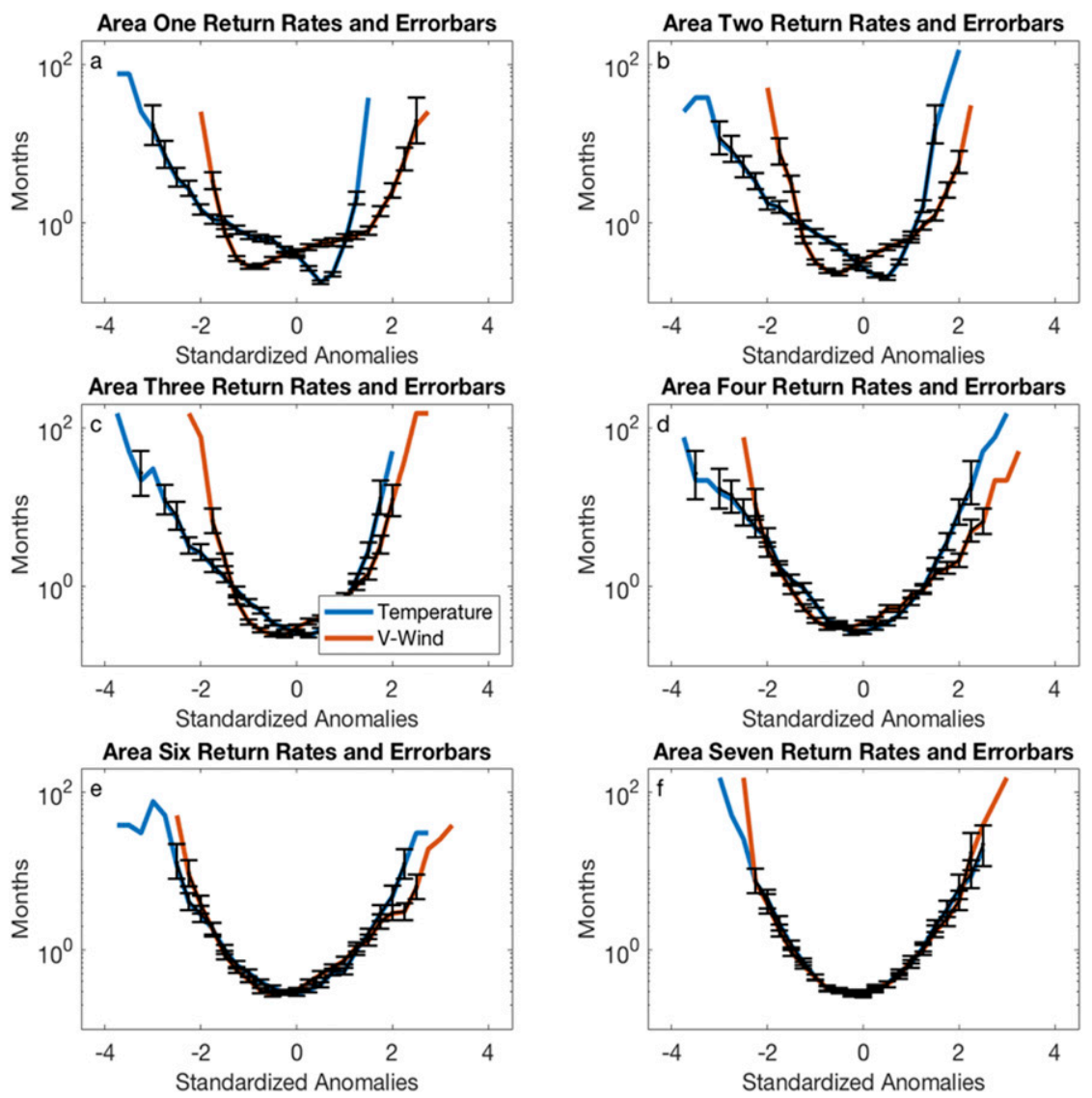

FIG. 5. Area-averaged return rates (months) for 925-hPa temperature and 925-hPa meridional wind standardized anomalies for areas 1, 2, 3, 4, 6, and 7, as defined in Fig. 3. The standardized anomalies were binned in 0.25 increments from -4 to +4 . A cutoff of the line before -4 or +4 signifies zero occurrences of an event in that particular bin. Error bars signify the 5 th and 95 th percentiles of the distribution, as determined using bootstrapping (1000 samples, with replacement).

centered on when the cold surge is located in the region being considered (Fig. 6).

On average, the identified strong cold-surge events lasted approximately 3 days, with the strongest event lasting 8 days (Fig. 7). A brief trend analysis is also conducted to test the impacts a changing climate may have on the occurrence of these strong cold surges, but no significant change over the last 38 years is identified. The mean standardized anomaly for all events at inception is +3.2 for $925-\mathrm{hPa}$ meridional wind and -3.5 for $925-\mathrm{hPa}$ temperature. The two share a linear relationship, which is highly inversely correlated with one another $(r<-0.8)$ along the cold-surge's track in the lee of the Andes Mountains (not shown). The northward propagation speed of the strong cold-surge events is also found to closely approximate that of a density current with depth of $1.5 \mathrm{~km}$ and virtual potential temperature perturbation of approximately $10 \mathrm{~K}\left[v \approx 22 \mathrm{~m} \mathrm{~s}^{-1}\right.$, as compared with $v \approx 15 \mathrm{~m} \mathrm{~s}^{-1}$ in
Garreaud (2000) and $v \approx 20 \mathrm{~m} \mathrm{~s}^{-1}$ in Colle and Mass (1995); not shown].

\section{b. Case study of the strongest identified cold-surge event (17-25 June 2001)}

The strongest identified cold-surge event occurred between 17 and 25 June 2001, lasting 8 days as it propagated northward in the lee of the Andes Mountains. To provide insight into individual cold-surge event structure and evolution, a brief case study of this event is conducted.

On day 1 (17 June 2001), or surge initiation day, 925-hPa temperature standardized anomalies from -2 to -3 occur in southern Bolivia and extreme northern Argentina (Fig. 8a). These large negative 925-hPa temperature standardized anomalies are collocated with $+2-+3$ 925-hPa meridional wind standardized anomalies (Fig. 9a). The anomalously southerly winds, and the relatively cold air they are transporting from higher latitudes, 

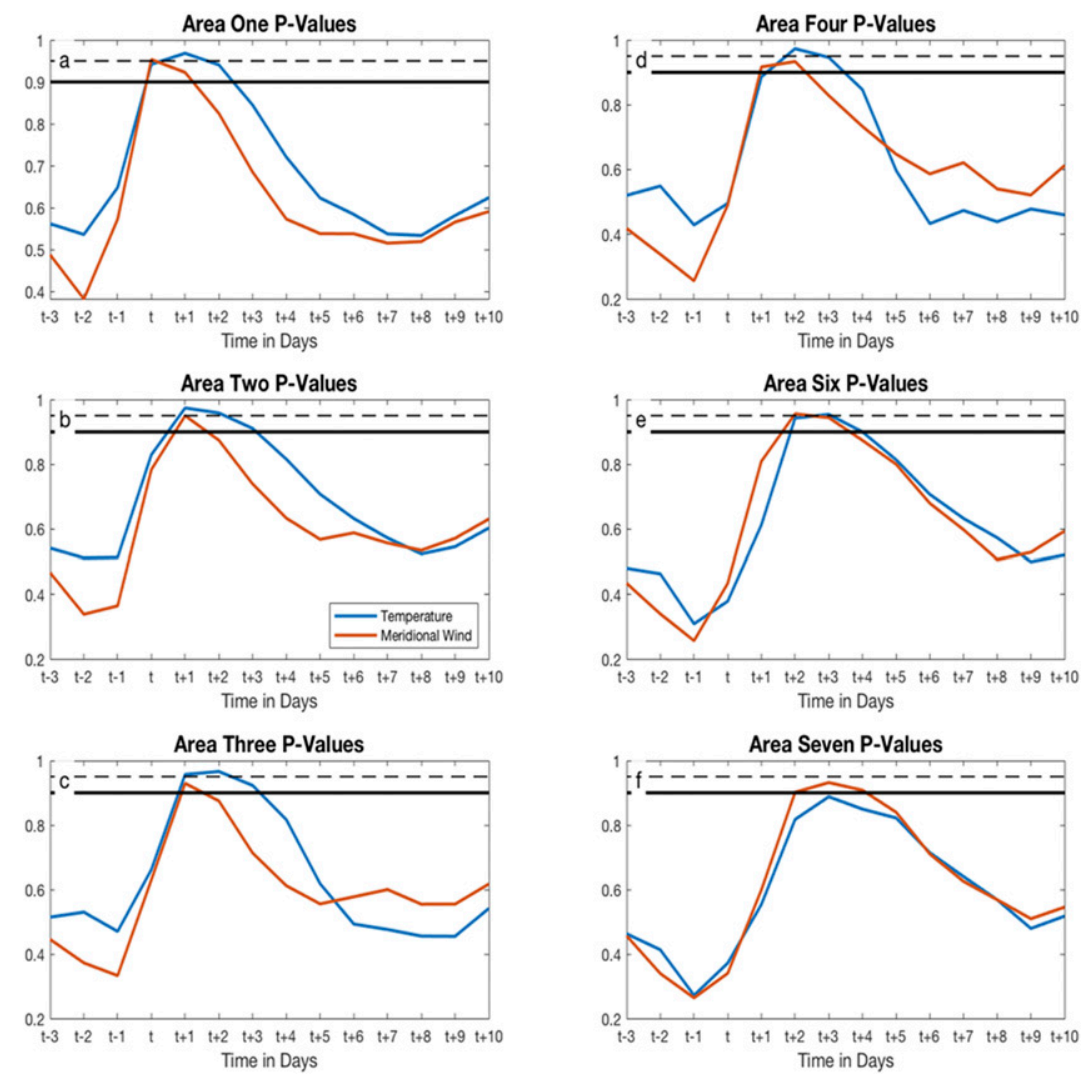

FIG. 6. The $p$ values obtained from Student's $t$ tests of the hypothesis that the 925-hPa temperature (blue lines) and 925-hPa meridional wind (red lines) standardized anomalies averaged over areas 1, 2, 3, 4, 6, and 7 (as defined in Fig. 3) are significantly different than zero. The analysis is conducted using 10000 bootstrapped samples of 67 cold-surge events over a period from 3 days before to 10 days after cold-surge initiation. The solid and dashed black lines represents $p$ values of 0.9 and 0.95 , respectively.

remain tightly bound to the Andes before entering the Amazon basin at lower latitudes (Figs. 8b-d, 9b-d).

On day 2 (18 June 2001), the cold surge has intensified, with 925-hPa temperature standardized anomalies of -4 and below and 925-hPa meridional wind standardized anomalies of +4 and above found into western Brazil, Bolivia, and extreme southern Peru (Figs. 8b, 9b). Terrain trapping is evident, with a westward bowing of the negative 925-hPa temperature standardized anomalies and positive $925-\mathrm{hPa}$ meridional wind standardized anomalies. This general structure and northward propagation were maintained for the subsequent two days (Figs. 8c,d, 9c,d).

On days 5 and 6 of this 8-day event (21-22 June 2001; Figs. 8e,f, 9e,f), 925-hPa temperature standardized anomalies from -2 to -3 encompass the entire Amazon basin, accompanied by raw $925-\mathrm{hPa}$ temperature as low as $16^{\circ} \mathrm{C}$. Strong surface sensible heat fluxes over the Amazon basin (not shown) have weakened and reduced the spatial extent of the negative standardized $925-\mathrm{hPa}$ temperature anomalies associated with the cold-surge event. However, the positive $925-\mathrm{hPa}$ meridional wind standardized anomalies are found farther to the north,

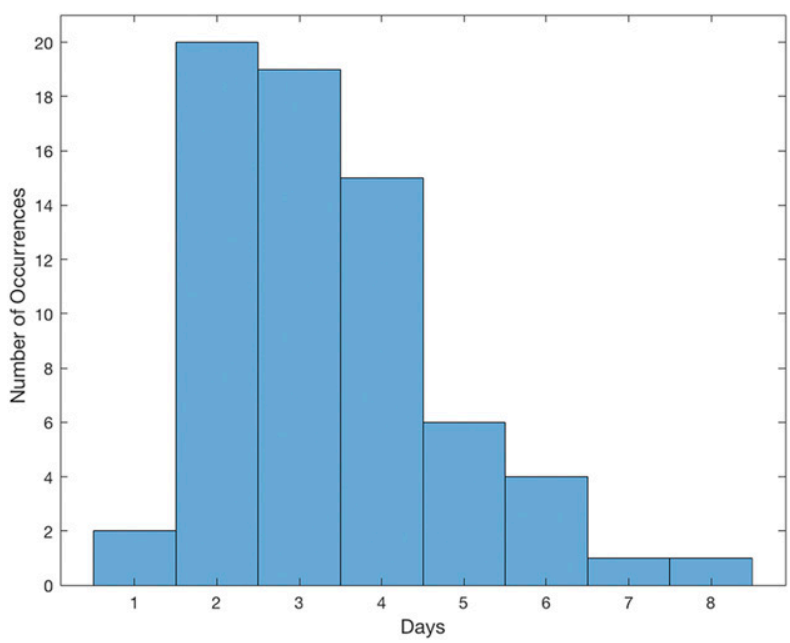

FIG. 7. The durations of all 67 events in the dataset, in days. 

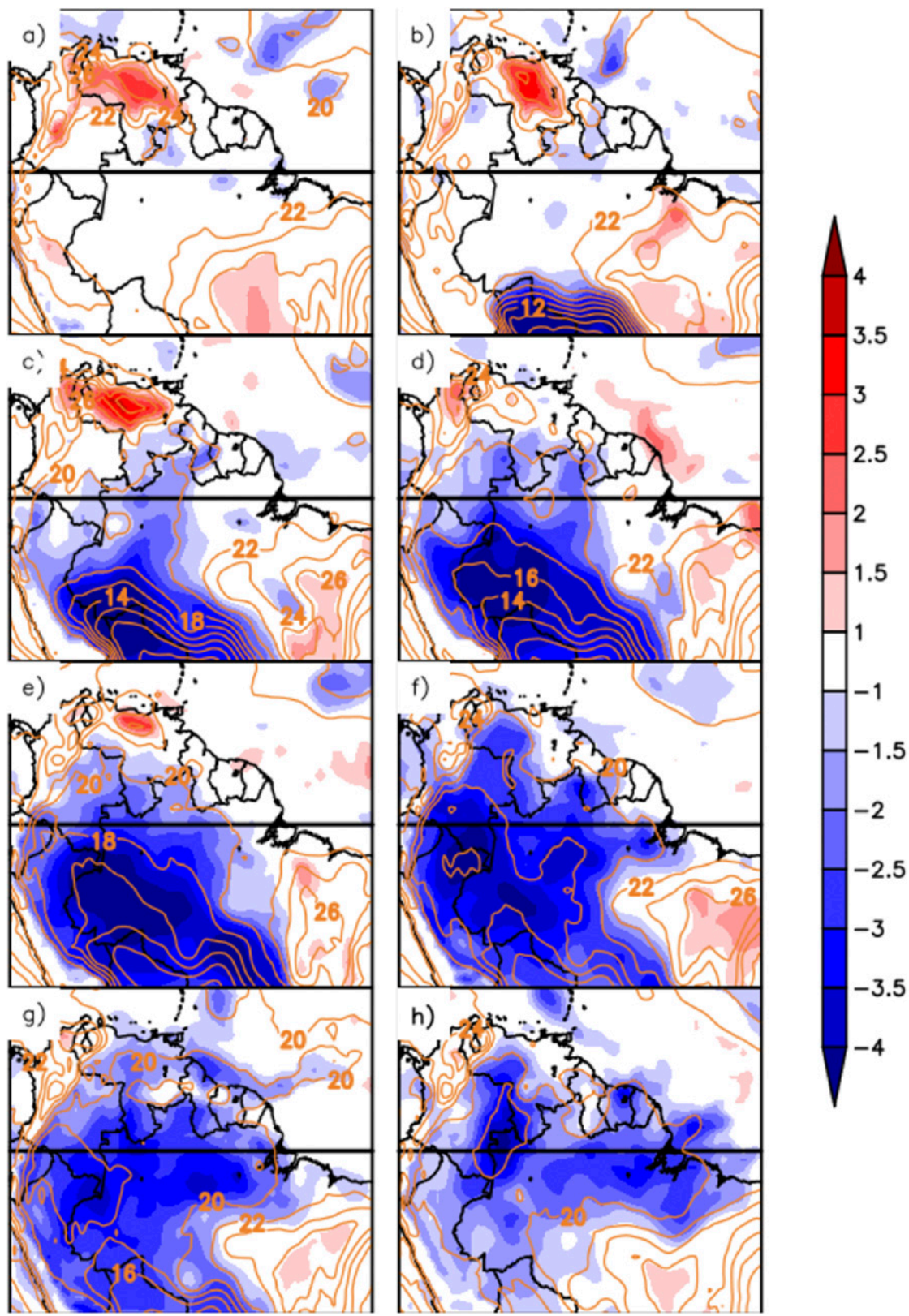

FIG. 8. The 925-hPa temperature standardized anomaly (unitless; color bar) and 925-hPa temperature $\left({ }^{\circ} \mathrm{C}\right.$; contoured) for the strongest cold-surge event in the dataset (17-25 Jun 2001), which lasted 8 days. (a)-(h) The patterns for 0000 UTC from day 1 (start) through day 8 (end) of the cold surge, respectively.

including to the southern Caribbean Sea, than their 925-hPa temperature counterparts (Figs. 9e,f).

Last, on days 7 and 8 (23-24 June 2001; Figs. 8g,h, 9g,h), the 925-hPa temperature standardized anomalies weaken as a result of continued surface sensible heating (Figs. 8g,h). The 925-hPa meridional wind standardized anomalies (Figs. 9g,h) curve slightly eastward as they interact with the elevated terrain of extreme northern Colombia and Venezuela (Fig. 3).
This terrain channeling generates an anomalous westerly component to the $925-\mathrm{hPa}$ horizontal wind over the extreme southern Caribbean Sea that dissipates a few days later (not shown).

\section{c. Composites for all 67 events}

While the previous case study provides insight into cold-surge behavior for the strongest event in the dataset, it is only somewhat representative of composite 

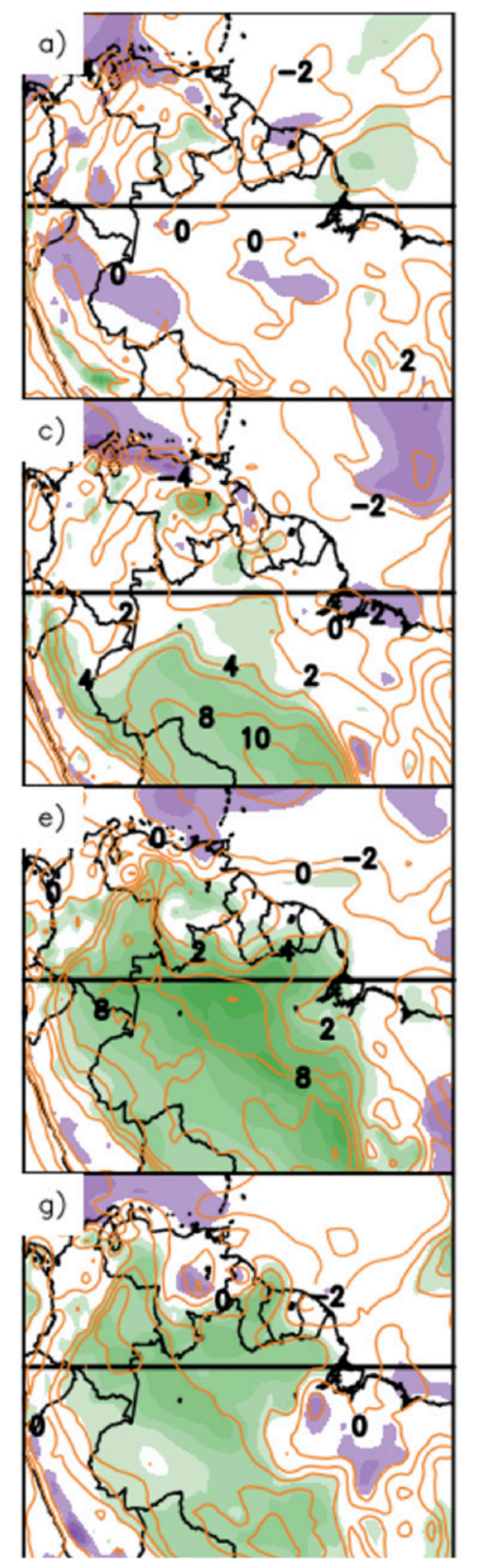

FIG. 9. As in Fig. 8, but for 925-hPa meridional wind $\left(\mathrm{m} \mathrm{s}^{-1}\right)$.
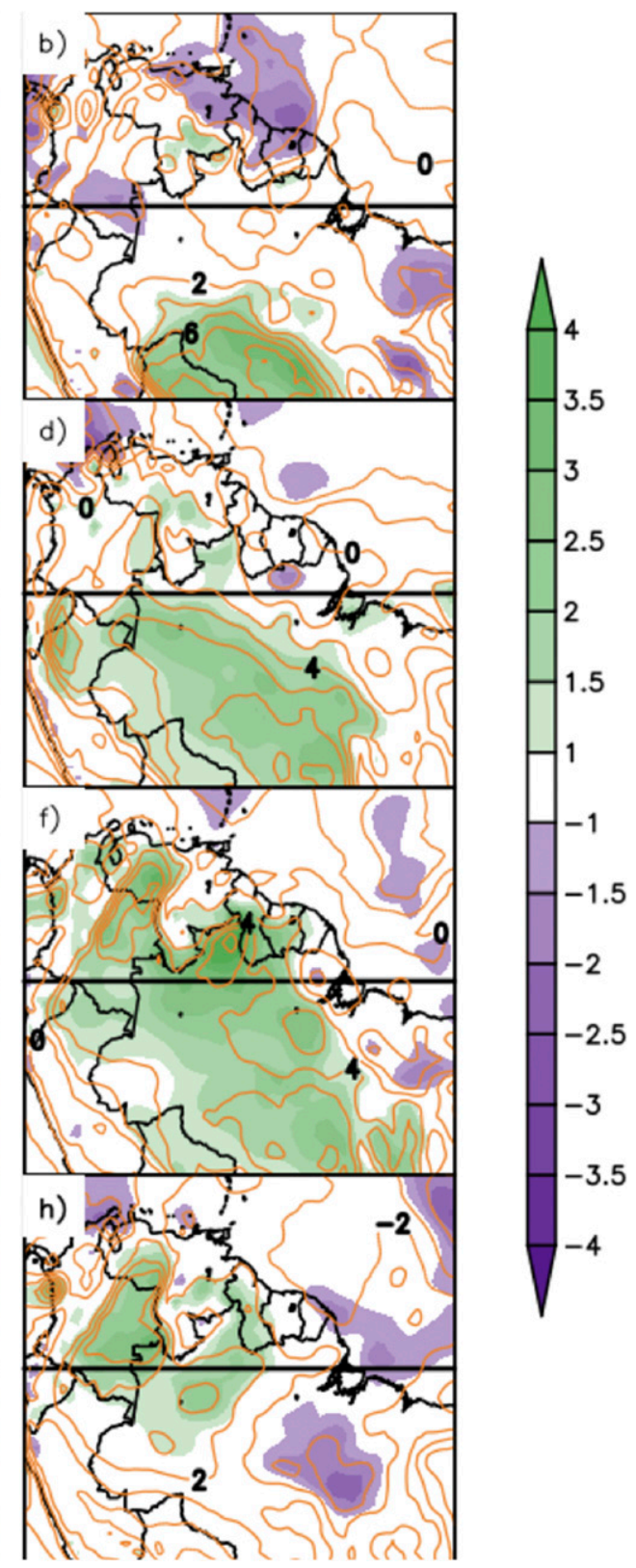

cold-surge behavior. Therefore, a more thorough treatment of all events is warranted.

As expected, composite-mean cold-surge intensity is less than that for the case study (Figs. 10,11). Further, differences in propagation speed, intensity, and areal expanse between individual cold-surge events (not shown) result in weaker peak composite-mean standardized anomaly magnitudes than when the peak standardized anomaly magnitudes of each event are composited. For example, although the composite-mean peak cold-surge intensity for $925-\mathrm{hPa}$ temperature over all 67 events is approximately -3.5 standard deviations, the largest composite-mean standardized anomaly magnitude is approximately -2.4 (Figs. 10c-e).

As time advances, the composite cold-surge event is consistently associated with anomalously cool temperatures at progressively farther north latitudes, with 0000 UTC $925-\mathrm{hPa}$ temperature composite-mean standardized anomalies of approximately -2.5 into the Amazon basin (Figs. 10d,e). For reference, these correspond to raw $925-\mathrm{hPa}$ temperature reductions of as much as $6^{\circ} \mathrm{C}$ relative to the presurge atmospheric state 


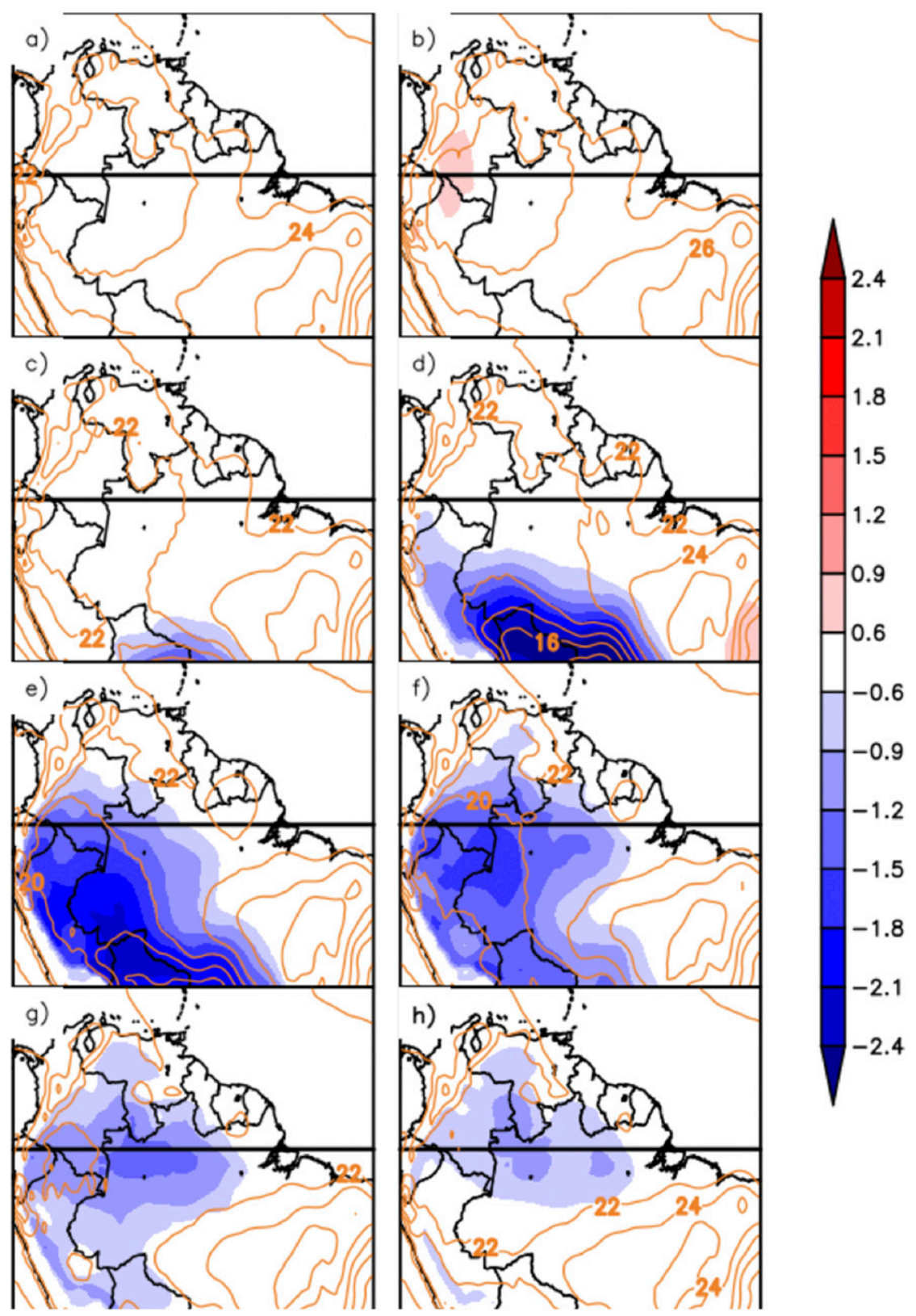

FIG. 10. Composite-mean 925-hPa temperature standardized anomaly (unitless; color bar) and 925-hPa temperature $\left({ }^{\circ} \mathrm{C}\right.$; contoured). (a)-(h) The composites that were generated daily at 0000 UTC from 2 days prior to cold-surge initiation to 5 days after cold-surge initiation, respectively.

(cf. Figs. 10a,b and 10c-e). As seen in the case study, anomalously cold 925 -hPa temperatures extend to the equator, albeit in a weakened state, by 3-4 days after cold-surge initiation (Fig. 10f), with the composite 925-hPa temperature negative standardized anomaly largely eliminated $4-5$ days after the start of the composite event (Figs. 10g,h).

A similar evolution is noted in the 925 -hPa meridional wind composite-mean standardized anomaly field: peak intensity in south-central South America, with rapid northward progression into and through the Amazon basin with subsequent decay in far northern South America (Fig. 11). However, the positive 925-hPa meridional wind composite-mean standardized anomaly advances equatorward more rapidly, and retains higher magnitudes in equatorial regions, than does the negative 925 -hPa temperature composite-mean standardized anomaly (cf. Figs. 10 and 11). An interesting 


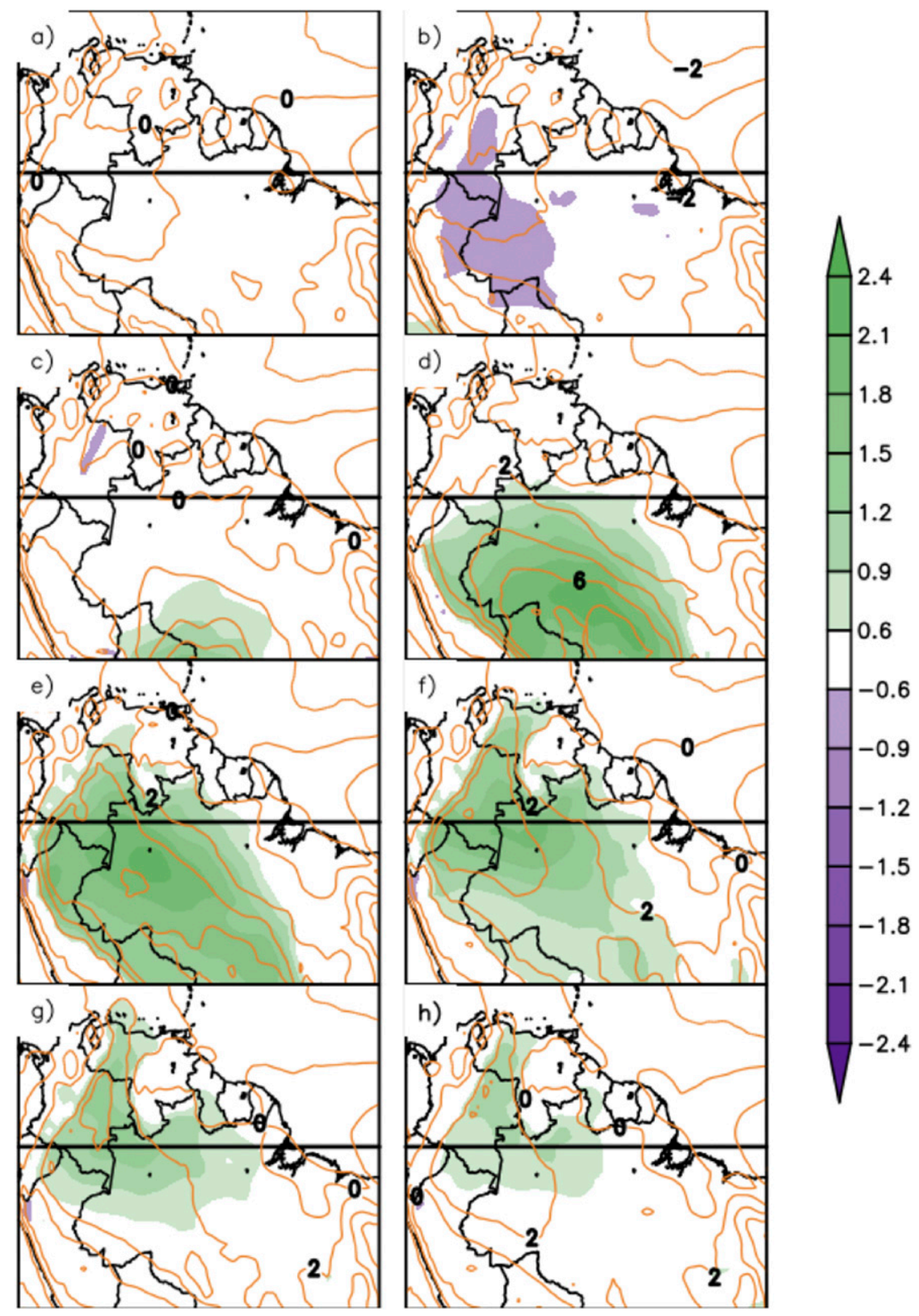

FIG. 11. As in Fig. 10, but for 925-hPa meridional wind $\left(\mathrm{m} \mathrm{s}^{-1}\right)$.

artifact of the meridional wind composites is the presence of positive anomalies over a narrow corridor extending northward from Venezuela toward the Caribbean Sea (Figs. 11f-h). The higher terrain of the Guiana shield in eastern Venezuela has elevations of $1000 \mathrm{~m}$ or greater (Fig. 3). The effects of these highlands can also be seen in southern Guyana, with a slight northward extension of anomalously southerly winds.

The cold-surge northward propagation speed varies between individual events. These differences in propagation speed result in variation in the time at which cold surges reach equatorial latitudes, in turn resulting in the composite-mean cold surge weakening in intensity but covering a larger area. To evaluate the extent to which this influences the analyses presented in Figs. 10 and 11, composites centered on the time of cold-surge dissipation are constructed (not shown). Composites of the 925-hPa temperature and meridional wind standardized anomalies are largely similar to those centered on the time of coldsurge initiation, with differences between the start- and end-based composites on the order of half a standardized anomaly or less (not shown). 

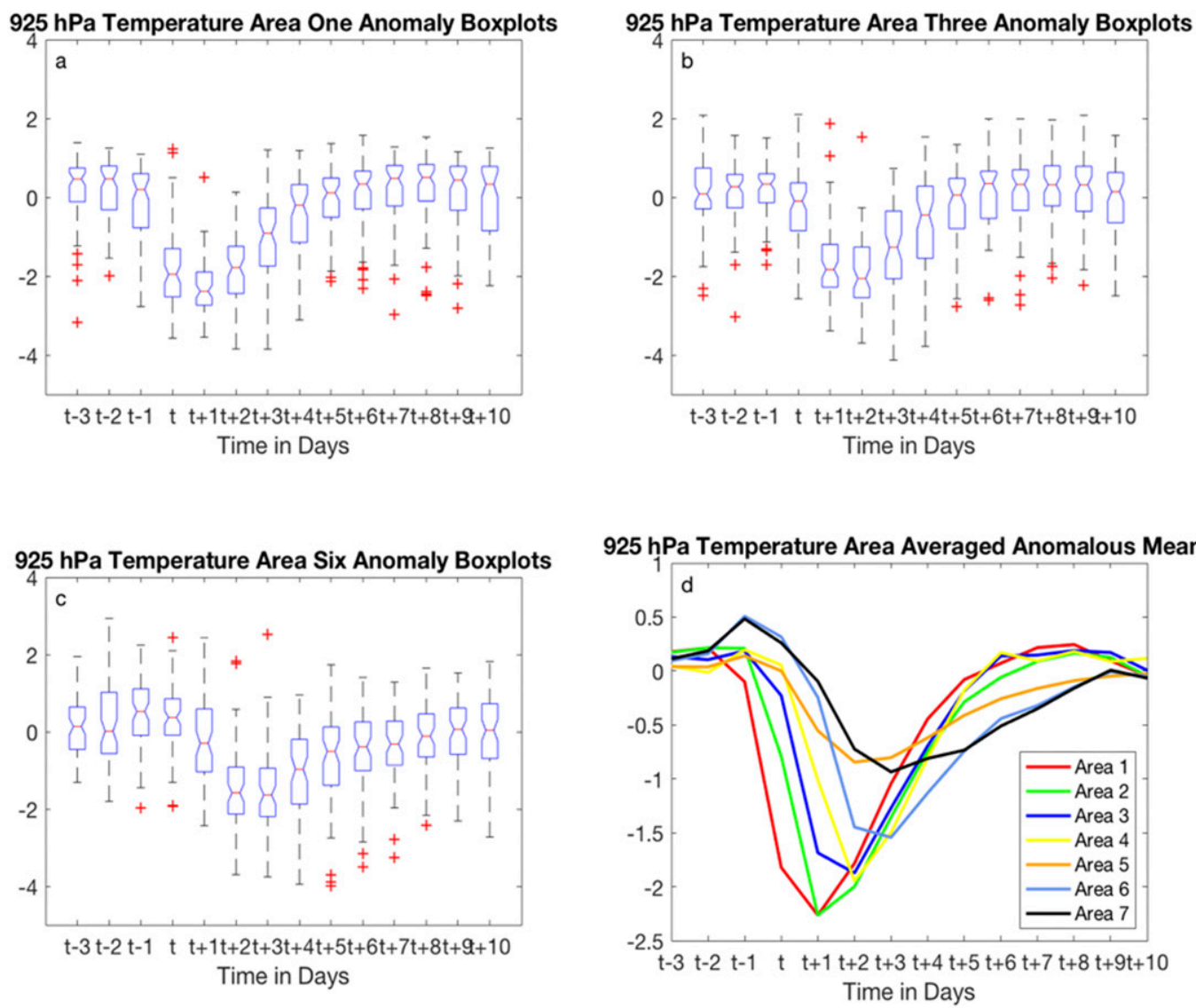

FIG. 12. Box plots of 925-hPa temperature standardized anomalies (unitless) for areas (top left) 1, (top right) 3 , and (bottom left) 6 (as defined in Fig. 3, with (bottom right) the means for all seven areas (colored per the legend in Fig. 3) plotted. The $x$ axis has units of days, with day $t$ representing the start of a cold-surge event. The red line in the middle represents the mean, with the blue box extending to the 25 th and 75 th percentiles. The dashed line shows the 10th and 90th percentiles, and plus signs represent outliers.

\section{d. Along-track area averages and variances}

Although the composites suggest that strong coldsurge events can modulate the atmosphere throughout much of the Amazon basin and into the southern Caribbean, it is imperative that the variance between cases is documented. To do so, area averages of selected fields (in terms of their standardized anomalies) are computed over each of the areas depicted in Fig. 3.

In the primary cold-surge initiation region (area 1 of Fig. 3), 925-hPa temperature is substantially decreased relative to days both before and after cold-surge initiation (Fig. 12a). At surge initiation, average reductions in 0000 UTC $925-\mathrm{hPa}$ temperature are on the order of $10^{\circ} \mathrm{C}$ (not shown), with abrupt temporal changes in the anomalous temperature compared to days before and after (Fig. 12d). Outliers present on the day of coldsurge initiation and the day after (i.e., time $t$ and $t+1$ ) are due to meridional variation in the exact position of a cold surge at the time of its initiation (not shown). The cold-surge identification criteria used in this study do not require a specific cold-surge origination location, such that a few of the identified events originated as far north as western Brazil to southern Peru (area 3 in Fig. 3). As the strong cold surges propagate northward, areaaveraged $925-\mathrm{hPa}$ temperature in the primary coldsurge origination region returns to its presurge state over the course of several days (Figs. 12a,d). Outliers at later time periods (e.g., 5-9 days after cold-surge initiation) primarily represent localized anomalously low 925-hPa temperature (Fig. 12a) collocated with anomalously southerly 925-hPa meridional wind (Fig. 13a). Since cold surges of any intensity occur approximately every 2 weeks year-round over subtropical South America (Garreaud 2000), these outliers are likely associated with subsequent weaker cold-surge events (not shown).

Farther to the north, the strong cold surges are associated with smaller $925-\mathrm{hPa}$ temperature standardized anomalies, but with diminished variability between 

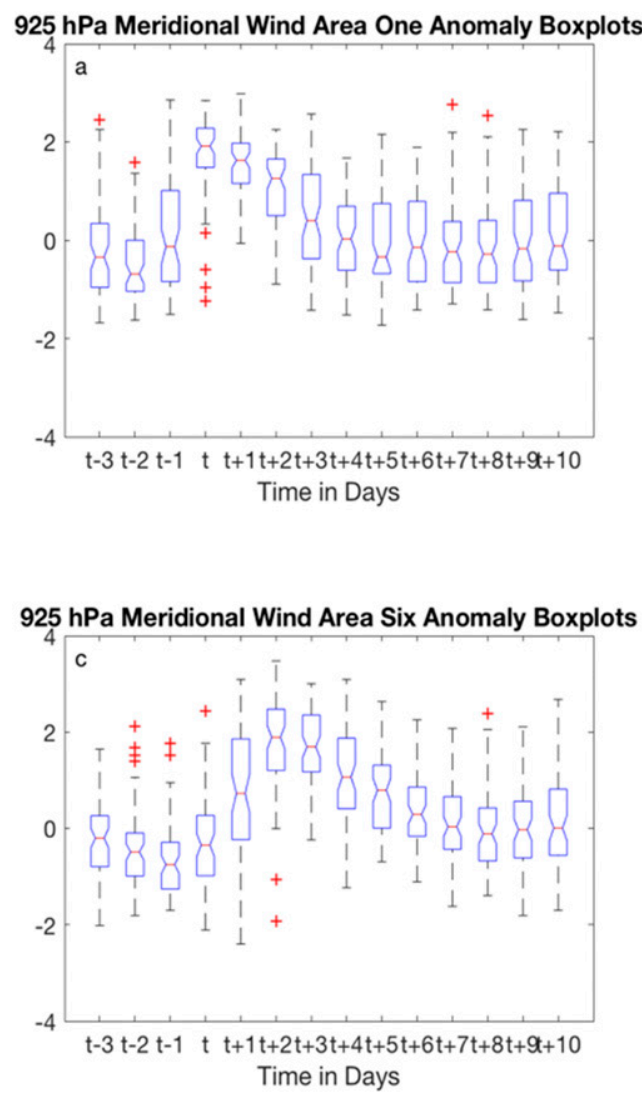

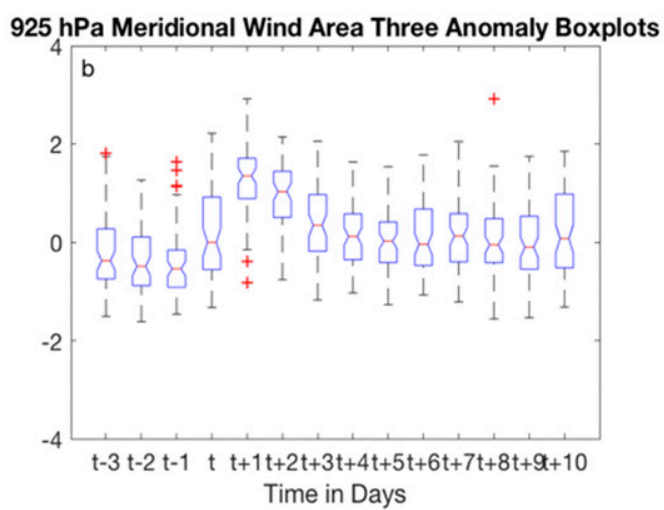

$925 \mathrm{hPa}$ Meridional Wind Area Averaged Anomalous Means

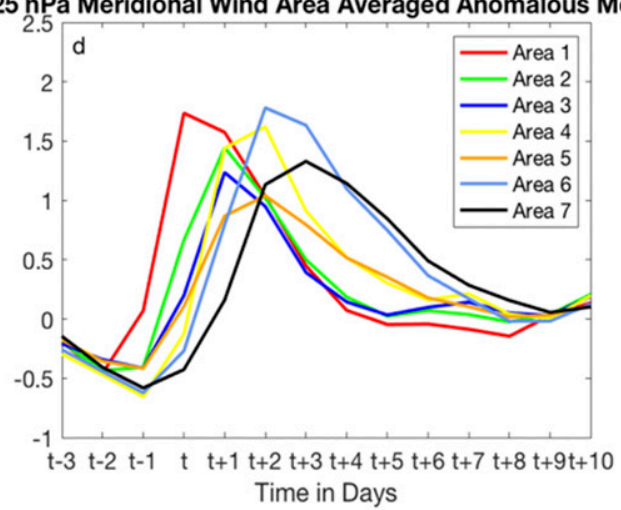

FIG. 13. As in Fig. 12, but for 925-hPa meridional wind.

events within the composite (Figs. 12b,c). By the time the surges have reached northwestern South America, they have lost much of their thermodynamic potency relative to climatology and are thus associated with smaller changes relative to the presurge atmospheric state (Figs. 12c,d). Across the entire Amazon basin (area 5 in Fig. 3), the 925-hPa temperature reduction in association with a strong cold surge is subtle [ -0.75 standard deviations (the orange line in Fig. 12d), or approximately $1^{\circ}-2^{\circ} \mathrm{C}$; not shown] but nevertheless documents the ability for these extreme events to modify lowertropospheric thermodynamic properties over one of the largest rain forest basins on Earth.

For the primary cold-surge initiation region, compositemean area-averaged 925-hPa meridional wind anomalies exceed +2 standardized anomalies at cold-surge initiation (Fig. 13a), with some outliers primarily consisting of cases with northerly winds. An analysis of these outliers indicates that they are the same cases that were outliers for $925-\mathrm{hPa}$ temperature at cold-surge initiation and represent a few events that were initiated atypically north as compared with the majority of identified strong cold-surge events. As the strong cold surges propagate northward, area-averaged $925-\mathrm{hPa}$ meridional wind in the primary cold-surge origination region returns to climatology, albeit not to the presurge atmospheric state characterized by slightly negative $925-\mathrm{hPa}$ meridional wind standardized anomalies, over the course of several days (Figs. 13a,d).

As cold surges propagate from western Brazil and southern Peru through to southern Colombia, areaaveraged $925-\mathrm{hPa}$ meridional wind standardized anomalies become less positive but also less variable (Figs. 13b,c), similar to what is observed for $925-\mathrm{hPa}$ temperature. Note that area-averaged $925-\mathrm{hPa}$ meridional wind standardized anomaly magnitudes become smaller at a less rapid rate than do area-averaged 925-hPa temperature standardized anomaly magnitudes (cf. Figs. 12 and 13). This is consistent with geostrophic adjustment on the synoptic-scale to the erosion of the $925-\mathrm{hPa}$ temperature anomalies by surface sensible heating over the Amazon basin. Across the entire Amazon basin, the area-averaged $925-\mathrm{hPa}$ meridional wind standardized anomaly exceeds +1 , corresponding to an area-averaged increase of over $2 \mathrm{~m} \mathrm{~s}^{-1}$ in areaaveraged $925-\mathrm{hPa}$ meridional wind, in association with 

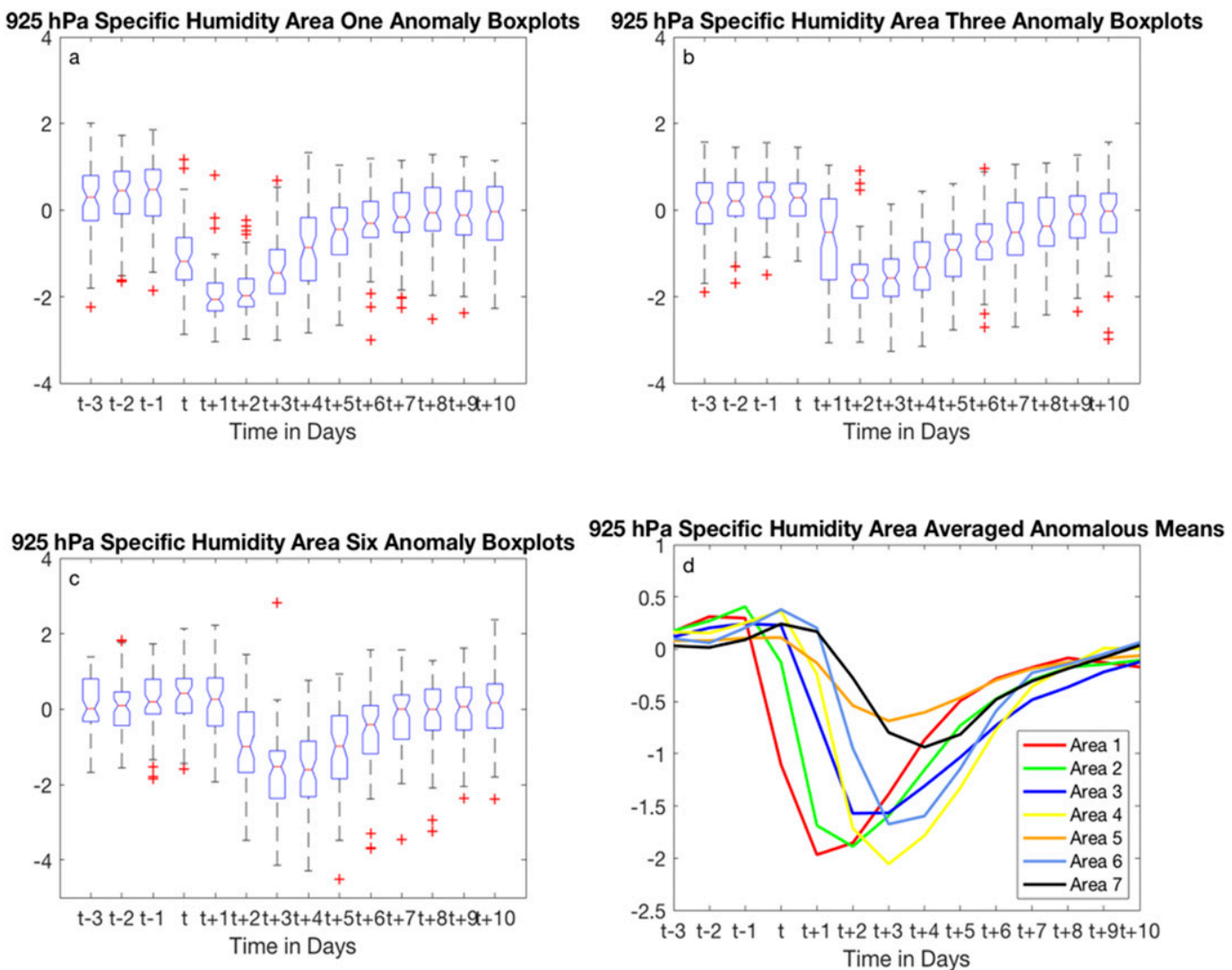

FIG. 14. As in Fig. 12, but for 925-hPa specific humidity.

the composite strong cold surge (Fig. 13d). Although this change is small in an absolute sense, it is associated with a large amount of anomalous kinetic energy over a $25^{\circ}$ latitude $\times 25^{\circ}$ longitude region with strong coldsurge events $\left(\sim 3 \times 10^{19} \mathrm{~J}\right)$.

Apart from the specific fields used to identify coldsurge events, strong cold-surge events modulate other kinematic and thermodynamic fields throughout the depth of the planetary boundary layer in the lee of the Andes for periods of 7-10 or more days. For example, strong cold-surge events are associated with negative area-averaged 925 -hPa specific humidity standardized anomalies (Fig. 14) and positive area-averaged mean sea level pressure standardized anomalies (Fig. 15). As with 925-hPa temperature and meridional wind, these standardized anomalies have the largest composite mean and greatest intracomposite variability near surge initiation (Figs. 14a, 15a), decreasing in both magnitude and intracomposite variation thereafter (Figs. 14c, 15c). Small negative 925-hPa meridional wind and mean sea level pressure anomalies in the 1-2 days preceding coldsurge initiation (Figs. 13a,d, 14a,d) are hypothesized to be associated with the passage of a synoptic-scale midlatitude cyclone immediately preceding the cold surge (e.g., Fig. 1; Pezza and Ambrizzi 2005). Similar to the 925-hPa meridional wind, mean sea level pressure standardized anomalies do not return to either climatology or the presurge state across northern South America within the 10 days following cold-surge initiation (Fig. 15d). This suggests that not only can strong cold surges modulate the lower-tropospheric environment as far north as the southern Caribbean, but they can have lasting effects over all of northern South America more than a week and a half after their initiation.

Cold-surge impacts are not felt only between the surface and $925 \mathrm{hPa}$. Along the path of the composite strong cold-surge, temperature standardized anomalies of -1 or less extend to approximately $600 \mathrm{hPa}$, with the deleterious effects of surface sensible heating over the Amazon basin manifest primarily in the sharp reduction of cold-surge intensity below $950 \mathrm{hPa}$ south of $5^{\circ} \mathrm{N}$ (Fig. 16, top). This results in an atypical vertical structure for the composite cold-surge event, as cold surges typically have maximum intensity at the surface due to density. In addition, temperature standardized anomalies of -1 or less extend as far north as $5^{\circ} \mathrm{N}$ between 900 and $750 \mathrm{hPa}$, suggesting increased static stability 

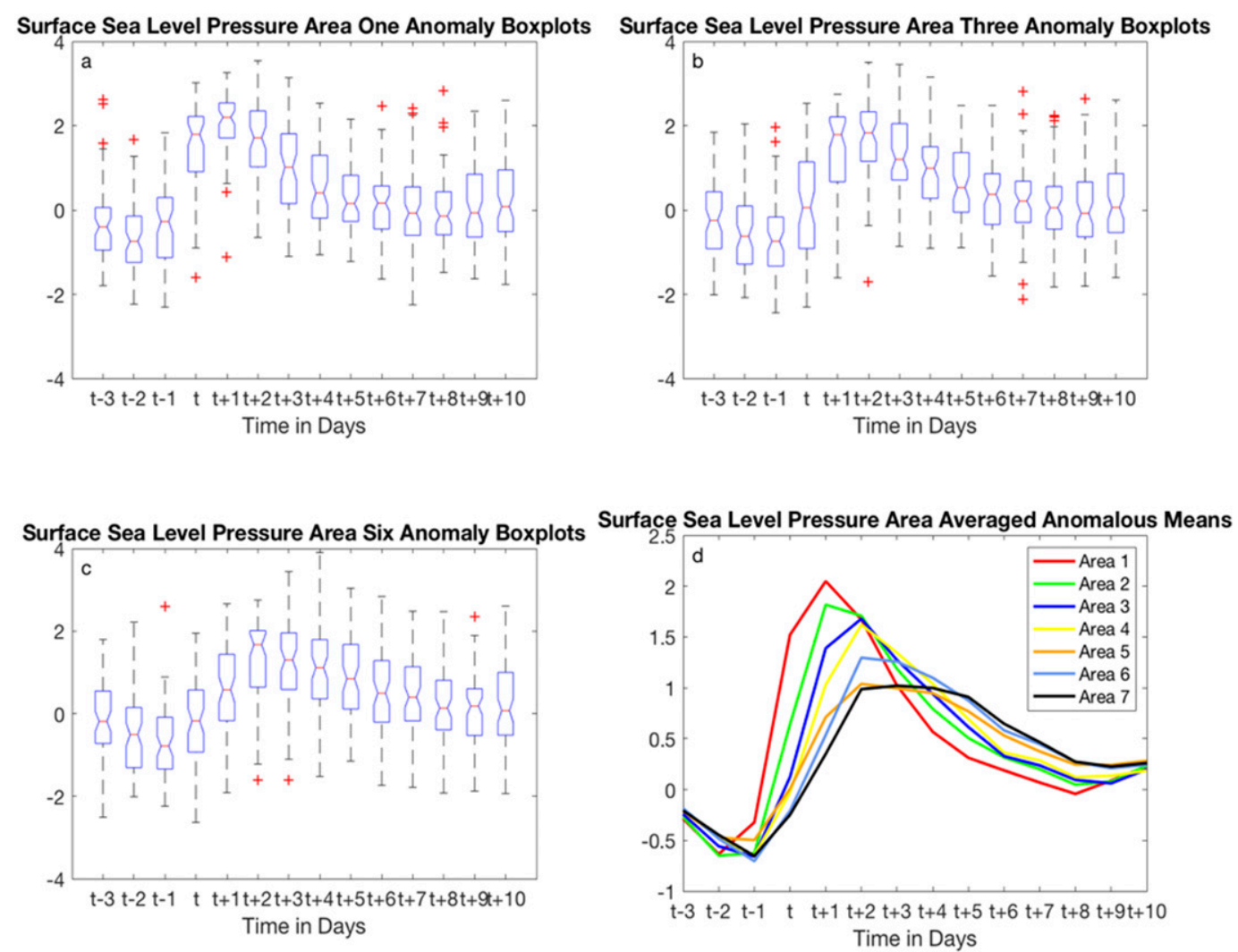

FIG. 15. As in Fig. 12, but for mean sea level pressure.

over the Amazon basin in association with strong cold-surge events (Fig. 16, top). In contrast, positive meridional wind standardized anomalies are primarily confined below $750 \mathrm{hPa}$, although their northward extent is similar to that for temperature (Fig. 16, bottom). As compared with surface sensible heating, friction exerts a comparatively minor influence on near-surface meridional wind standardized anomalies compared to at higher altitudes in the planetary boundary layer.

\section{Conclusions and future work}

This study presents an in-depth climatology of strong South American cold surges in the lee of the Andes Mountains, emphasizing the extent to which strong cold-surge events modify meso- $\alpha$ - to synopticscale kinematic and thermodynamic fields relative to the spatiotemporally varying climatology as the surges propagate northward. It is shown that strong South American cold surges which follow the Andean pathway not only affect the thermodynamic and kinematic fields deep into the tropics but can cause changes to the mean properties of the northern South American lower troposphere long after the cold surge has dissipated.
Using 925-hPa meridional wind and temperature standardized anomalies, 67 strong cold-surge events are identified. On average, these 67 events transport anomalously cold air (with standardized anomalies of -3 or lower) by way of anomalously southerly winds (with standardized anomalies of +3 or higher). As these strong cold surges progress northward over the course of 2-8 days, they are weakened, both in an absolute sense and in terms of standardized anomalies, through surface sensible heating over the warm Amazon River basin. Consistent with geostrophic adjustment, near-surface meridional wind standardized anomalies become smaller over northern South America in response to, rather than preceding, changes in the near-surface temperature standardized anomalies.

Previous studies have suggested Andean cold surges as a potential pathway by which midlatitude southern Pacific Ocean synoptic-scale phenomena can influence preexisting and/or initiate new equatorial waves, particularly Kelvin waves, many days later (e.g., Liebmann et al. 2009, Griffin 2012). To examine whether a robust connection exists between the 67 strong cold-surge events identified in this work and subsequent Kelvin wave activity, National Oceanic and Atmospheric Administration Climate Data Record daily outgoing 


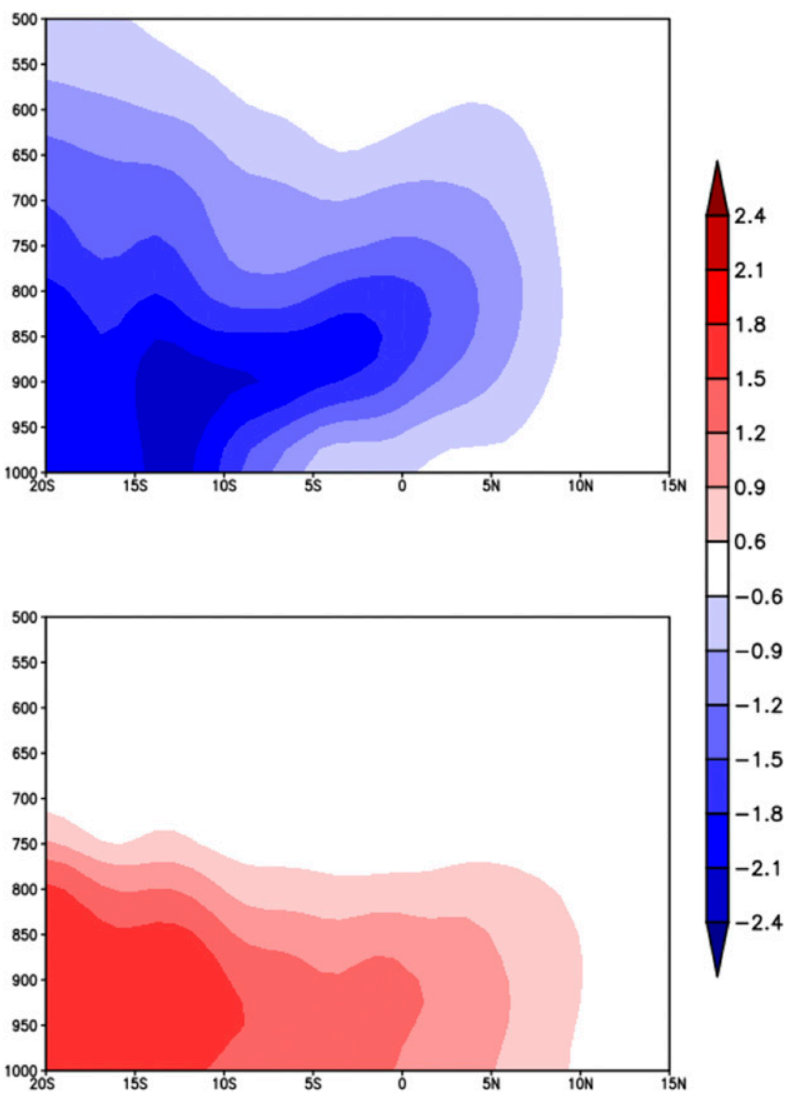

FIG. 16. Composite vertical cross section for standardized anomalies (unitless) of (top) temperature and (bottom) meridional wind. The $x$ axis is spatiotemporal in the sense that the values shown here are for the minimum value at the nearest time (0000 UTC for each $1^{\circ}$ latitude) as the cold surges travel northward.

longwave radiation data (Lee 2014) are filtered following Wheeler and Kiladis (1999). Through this analysis, no reliable connection is identified between strong Andean cold surges and either preexisting or in situ generated convectively coupled Kelvin waves (not shown). This analysis does not preclude the possibility that coldsurge events can trigger and/or interfere with existing convectively coupled Kelvin waves, but further research is necessary to quantify the frequency with which coldsurge events may trigger or interfere with Kelvin waves and the physical processes by which they may do so.

Furthermore, it has been shown that cold surges in eastern Asia can incite new and/or interfere with preexisting synoptic-scale disturbances in the western North Pacific Ocean (e.g., Chang and Lau 1980; Wang and Chen 2014). The potential impact of strong Andean cold surges on synoptic-scale disturbances, such as African easterly waves, in the Caribbean Sea and tropical North Atlantic Ocean is also briefly investigated. None of the 67 events in this dataset has a detectable

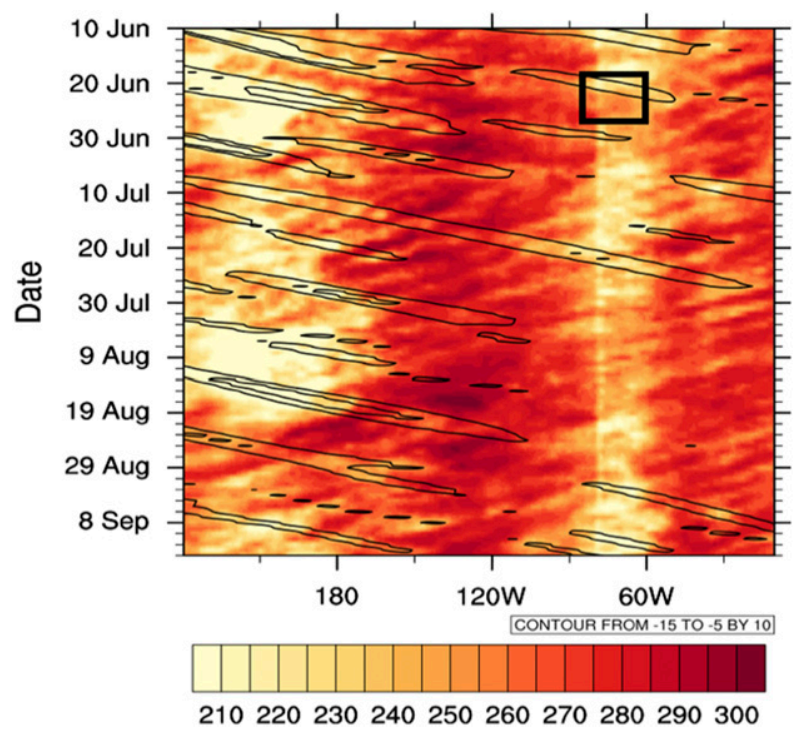

FIG. 17. Hövmoller diagram of outgoing longwave radiation $\left(\mathrm{W} \mathrm{m}^{-2}\right.$ ) from $120^{\circ} \mathrm{E}$ to $120^{\circ} \mathrm{W}$ from 10 Jun 2001 through 15 Sep 2001 averaged from $7.5^{\circ} \mathrm{S}$ to $7.5^{\circ} \mathrm{N}$. Solid black lines indicate Kelvin waves identified in the wavenumber/frequency-filtered outgoing longwave radiation field. The black box represents the approximate longitude of the Amazon basin, and the time of occurrence of the strongest event in the dataset (17-25 Jun 2001).

(subject to limitations of the data used in this study) interaction with a preexisting African easterly wave or is shown to incite a new tropical disturbance (not shown). Figure 17 shows that even the strongest cold surge in the dataset has little to no impact on the outgoing longwave radiation over the Amazon basin, thus little to no enhancement to/formation of any equatorial disturbances in the area. Again, this analysis does not preclude the possibility that strong Andean cold surges may incite new and/or interfere with preexisting synoptic-scale disturbances in the Caribbean Sea and tropical North Atlantic Ocean. Indeed, anomalous southerly flow associated with strong Andean cold surges does extend into the southern Caribbean Sea in the composite mean (Figs. 10, 12). However, future research is necessary to quantify the extent to which strong Andean cold surges incite new and/or interfere with preexisting synoptic-scale disturbances in the Caribbean and Atlantic and to identify the physical processes by which they may do so.

This study identifies the strongest 67 Andean coldsurge events from 1980 to 2017 and showed that these potent events can largely survive the strong heating from the Amazon basin below, particularly above the surface layer, and propagate to as far north as $5^{\circ}-10^{\circ} \mathrm{N}$ before dissipation. Compared with previous studies of South American cold surges (e.g., Garreaud 2000; Lupo et al. 2001; Pezza and Ambrizzi 2005; Metz et al. 2013), this 
study identifies a similar frequency of intense cold-surge events, with similar cold-surge structures and resulting societal impacts to the cold surges identified in those studies. This study advances on previous work by providing a climatology of the 67 most potent cold-surge events for the South American Andean pathway from 1980 to 2017 (the most recent 38-yr climatological period of record) at an unprecedented level of detail and specifically provides new insight into how these highly anomalous events interact with one of the largest tropical rain forests on the planet.

Future directions of study include applying the standardized anomaly methodology to other cold-surge pathways in South America and elsewhere, potentially leading to the first internally consistent global cold-surge climatology. Other future research may include conducting highresolution, convection-allowing numerical simulations of selected strong cold-surge events to examine impacts of cold surges on deep, moist convection over the Amazon basin, including impacts upon existing or the in situ generation of new convectively coupled equatorial waves.

Acknowledgments. This research greatly benefited from conversations with and input from Kyle Griffin (RiskPulse), Zachary Handlos (Georgia Institute of Technology), Jonathan Kahl (UWM), Sergey Kravtsov (UWM), and Brian Tang (University at Albany), as well as feedback from Nicholas Metz (Hobart and William Smith Colleges) and two anonymous reviewers. We acknowledge use of NCL routines by Carl Schreck (North Carolina State University) in the identification of Kelvin waves in wavenumber/frequency-filtered outgoing longwave radiation data.

\section{REFERENCES}

Chang, C.-P., and K. M. W. Lau, 1980: Northeasterly cold surges and near-equatorial disturbances over the winter MONEX area during December 1974. Part II: Planetary-scale aspects. Mon. Wea. Rev., 108, 298-312, https://doi.org/10.1175/15200493(1980)108<0298:NCSANE > 2.0.CO;2.

Colle, B. A., and C. Mass, 1995: The structure evolution of cold surges east of the Rocky Mountains. Mon. Wea. Rev., 123, 2577-2610, https://doi.org/10.1175/1520-0493(1995)123<2577: TSAEOC $>2.0 . \mathrm{CO} ; 2$.

Crossett, C., and N. Metz, 2017: A climatological study of extreme cold surges along the African highlands. J. Appl. Meteor. Climatol., 56, 1731-1738, https://doi.org/10.1175/JAMC-D-150191.1.

Dee, D., and Coauthors, 2011: The ERA-Interim reanalysis: Configuration and performance of the data assimilation system. Quart. J. Roy. Meteor. Soc., 137, 553-597, https://doi.org/ 10.1002/qj.828.

Doty, B., and J. L. Kinter III, 1992: The Grid Analysis and Display System (GrADS): A practical tool for Earth science visualization. Preprints, Eighth Int. Conf. on Interactive Information and Processing Systems, Atlanta, GA, Amer. Meteor. Soc., $115-116$.

Garreaud, R., 2000: Cold air incursions over subtropical South America: mean structure and dynamics. Mon. Wea. Rev., 128 , 2544-2559, https://doi.org/10.1175/1520-0493(2000)128<2544: CAIOSS $>2.0 . \mathrm{CO} ; 2$.

Griffin, K. S., 2012: Large-scale influences on the pre-genesis of tropical cyclone Karl (2010). M.S. thesis, Dept. of Atmospheric and Environmental Sciences, University at Albany, State University of New York, 108 pp.

Grumm, R. H., and R. Hart, 2001: Standardized anomalies applied to significant cold season weather events: Preliminary findings. Wea. Forecasting, 16, 736-754, https://doi.org/10.1175/15200434(2001)016<0736:SAATSC>2.0.CO;2.

Hart, R. E., and R. H. Grumm, 2001: Using normalized climatological anomalies to rank synoptic-scale events objectively. Mon. Wea. Rev., 129, 2426-2442, https://doi.org/10.1175/15200493(2001)129<2426:UNCATR > 2.0.CO;2.

Hsu, H. H., 1987: Propagation of low-level circulation features in the vicinity of mountain ranges. Mon. Wea. Rev., 115, 1864-1891, https://doi.org/10.1175/1520-0493(1987)115<1864: POLLCF $>2.0 . C O ; 2$.

Junker, N. W., M. J. Brennan, F. Pereira, M. J. Bodner, and R. H. Grumm, 2009: Assessing the potential for rare precipitation events with standardized anomalies and ensemble guidance at the Hydrometeorological Prediction Center. Bull. Amer. Meteor. Soc., 90, 445-453, https://doi.org/ 10.1175/2008BAMS2636.1.

Leathers, D. L., 1986: Edge wave characteristics of East Asian cold surges. M.S. thesis, Dept. of Meteorology, The Pennsylvania State University, 108 pp.

Lee, H.-T., 2014: Climate algorithm theoretical basis document (C-ATBD): Outgoing longwave radiation (OLR)—Daily. NOAA Climate Data Record (CDR) Program Doc. CDRPATBD-0526, 46 pp. http://www1.ncdc.noaa.gov/pub/data/sds/ cdr/CDRs/Outgoing\%20Longwave\%20Radiation\%20-\%20Daily/ AlgorithmDescription.pdf.

Li, W., and R. Fu, 2006: Influence of cold air intrusions on the wet season onset over Amazonia. J. Climate, 19, 257-275, https:// doi.org/10.1175/JCLI3614.1.

Liebmann, B., G. N. Kiladis, L. M. V. Carvalho, C. Jones, C. S. Vera, I. Blade, and D. Allured, 2009: Origin of convectively coupled Kelvin waves over South America. J. Climate, 22, 300-315, https://doi.org/10.1175/2008JCLI2340.1.

Lupo, A. R., J. J. Nocera, L. F. Bosart, E. G. Hoffman, and D. J. Knight, 2001: South American cold surges: Types, composites and case studies. Mon. Wea. Rev., 129, 1021-1041, https://doi.org/ 10.1175/1520-0493(2001)129<1021:SACSTC $>2.0 . C O ; 2$.

Mass, C. F., and M. D. Albright, 1987: Coastal southerlies and alongshore surges of the west coast of North America: Evidence of mesoscale topographically trapped response to synoptic forcing. Mon. Wea. Rev., 115, 1707-1738, https://doi.org/ 10.1175/1520-0493(1987)115<1707:CSAASO>2.0.CO;2.

MathWorks, 2018: MATLAB: Global Optimization Toolbox User's Guide (r2018a). MathWorks Rep., 756 pp., http://www. mathworks.com/help/pdf_doc/gads/gads_tb.pdf.

Metz, N., H. M. Archambault, A. F. Srock, T. J. Galarneau Jr., and L. Bosart, 2013: A comparison of South American and African preferential pathways for extreme cold events. Mon. Wea. Rev., 141, 2066-2086, https://doi.org/10.1175/MWR-D-1200202.1.

Müller, G. V., and G. J. Berri, 2007: Atmospheric circulation associated with persistent generalized frosts in central-southern 
South America. Mon. Wea. Rev., 135, 1268-1289, https://doi.org/ 10.1175/MWR3344.1.

Pezza, A. B., and T. Ambrizzi, 2005: Dynamical conditions and synoptic tracks associated with different types of cold surge over tropical South America. Int. J. Climatol., 25, 215-241, https://doi.org/10.1002/joc.1080.

Sprenger, M., O. Martius, and J. Arnold, 2013: Cold surge episodes over southeastern Brazil-A potential vorticity perspective. Int. J. Climatol., 33, 2758-2767, https://doi.org/10.1002/ joc.3618.

Tilley, J. S., 1990: On the application of edge wave theory to terrain-bounded cold surges: A numerical study. Ph.D thesis, The Pennsylvania State University, $353 \mathrm{pp}$.

Torn, R. D., and G. J. Hakim, 2008: Ensemble-based sensitivity analysis. Mon. Wea. Rev., 136, 663-677, https://doi.org/10.1175/ 2007MWR2132.1.
Vera, C., P. K. Vigliarolo, and E. H. Berbery, 2002: Cold season synoptic-scale waves over subtropical South America. Mon. Wea. Rev., 130, 684-699, https://doi.org/10.1175/1520-0493(2002) $130<0684$ :CSSSWO $>2.0 . \mathrm{CO} ; 2$.

Wang, H., and R. Fu, 2004: Influence of cross-Andes flow on the South American low-level jet. J. Climate, 17, 1247-1262, https://doi.org/10.1175/1520-0442(2004)017<1247:IOCFOT> 2.0.CO;2.

Wang, L., and W. Chen, 2014: An intensity index for the East Asian winter monsoon. J. Climate, 27, 2361-2374, https://doi.org/ 10.1175/JCLI-D-13-00086.1.

Wheeler, M., and G. N. Kiladis, 1999: Convectively coupled equatorial waves: Analysis of clouds and temperature in the wavenumber-frequency domain. J. Atmos. Sci., 56, 374-399, https://doi.org/10.1175/1520-0469(1999)056<0374:CCEWAO > 2.0.CO;2. 